IZA DP No. 7460

Regional Effect Heterogeneity of Start-Up Subsidies for the Unemployed

Marco Caliendo

Steffen Künn

June 2013 


\title{
Regional Effect Heterogeneity of Start-Up Subsidies for the Unemployed
}

\author{
Marco Caliendo \\ University of Potsdam,
}

IZA, DIW Berlin and IAB Nuremberg

Steffen Künn

IZA

\author{
Discussion Paper No. 7460 \\ June 2013
}

IZA

P.O. Box 7240
53072 Bonn
Germany

Phone: +49-228-3894-0

Fax: +49-228-3894-180

E-mail: iza@iza.org

\begin{abstract}
Any opinions expressed here are those of the author(s) and not those of IZA. Research published in this series may include views on policy, but the institute itself takes no institutional policy positions. The IZA research network is committed to the IZA Guiding Principles of Research Integrity.

The Institute for the Study of Labor (IZA) in Bonn is a local and virtual international research center and a place of communication between science, politics and business. IZA is an independent nonprofit organization supported by Deutsche Post Foundation. The center is associated with the University of Bonn and offers a stimulating research environment through its international network, workshops and conferences, data service, project support, research visits and doctoral program. IZA engages in (i) original and internationally competitive research in all fields of labor economics, (ii) development of policy concepts, and (iii) dissemination of research results and concepts to the interested public.
\end{abstract}

IZA Discussion Papers often represent preliminary work and are circulated to encourage discussion. Citation of such a paper should account for its provisional character. A revised version may be available directly from the author. 


\section{ABSTRACT \\ Regional Effect Heterogeneity of Start-Up Subsidies for the Unemployed ${ }^{*}$}

Recent microeconometric evaluation studies have shown that start-up subsidies for unemployed individuals are an effective policy tool to improve long-term employment and income prospects of participants, in particular compared to other active labor market programs (e.g. training, job search assistance or job creation schemes). What has not been examined yet are the potentially heterogeneous effects of start-up programs across regional labor markets. Labor demand side restrictions in areas with relatively bad labor market conditions generally increase entries into start-up programs as job offers are limited and starting an own business is an opportunity to leave unemployment. However, the survival of firms in deprived areas is also lower, such that the overall effect remains an empirical question. We use a combination of administrative and survey data and observe participants in two distinct start-up programs in Germany for five years after start-up as well as a control group of unemployed who did not enter these programs. We add information on unemployment rates and GDP per capita at the labor agency district level to distinguish regional labor markets. Using propensity score matching methods we find supportive evidence that the founding process and development of businesses as well as program effectiveness is influenced by prevailing economic conditions at start-up.

JEL Classification: J68, R11, C14, H43, L26

Keywords: start-up subsidies, evaluation, effect heterogeneity, regional effects, self-employment

Corresponding author:

Marco Caliendo

University of Potsdam

Chair of Empirical Economics

August-Bebel-Str. 89

14482 Potsdam

Germany

E-mail: caliendo@uni-potsdam.de

\footnotetext{
* The authors thank Michael Fritsch and David Storey for valuable comments. Financial support of the IAB (Nuremberg) under the research grant No. 1007 is gratefully acknowledged.
} 


\section{Introduction}

The promotion of self-employment among unemployed individuals has been shown to be an effective strategy as part of active labor market policies (ALMP). The main idea is to provide unemployed individuals financial assistance in order to set up their own business and therefore to escape unemployment. Furthermore, start-up subsidies in contrast to other programs of ALMP are potentially associated with a "double dividend", if the subsidized businesses create additional jobs in the future and hence reducing unemployment further. The justification of start-up subsidies for unemployed individuals is based on the existence of disadvantages for nascent unemployed entrepreneurs. These might arise due to capital constraints, shortages in start-up specific human capital or the abscence of job-related (and social) networks as well as imperfect information or higher shares of necessity startups (when compared to "regular" business start-ups not coming from unemployment). For instance, capital markets are particularly likely to discriminate against unemployed individuals which restricts access to loans (Meager, 1996; Perry, 2006); restricted access to information about business opportunities might lead unemployed individuals to realize less valuable business ideas (Shane, 2003). The subsidy therefore aims at helping nascent unemployed entrepreneurs to overcome existing barriers due to their unemployment status.

The overall international evidence on the effectiveness of traditional ALMP programs such as training, job creation schemes or job search assistance with respect to income and employment prospects is rather disappointing, even if occasionally positive effects are identified (see Martin and Grubb, 2001; Dar and Gill, 1998; Dar and Tzannatos, 1999; or Fay, 1996 for evidence on OECD countries and Kluve and Schmidt, 2002 for the European experience). In contrast, start-up subsidies seem to be more promising. A recent study by Caliendo and Künn (2011) shows that such programs improve long-term employment and income prospects of participants and are particularly effective for disadvantaged groups in the labor market, such as low educated or young individuals who generally face limited job offers as their outside options are very limited. In addition to the positive impact on participant's labor market prospects, we also know that firm foundation can be of major importance for regional development as it has a positive impact on the structural change, innovation, job creation and hence economic growth (see Storey, 1994; Audretsch and Keilbach, 2004; Fritsch, 2008).

However, what has not been examined yet is to what extent prevailing local economic conditions influence the effectiveness of start-up subsidies as an ALMP program. Existing evidence on the effectiveness of traditional ALMP programs (e.g. training, wage subsidies) with respect to economic conditions suggests that programs are generally more effective in regions with unfavorable economic conditions (see Lechner and Wunsch, 2009; Fahr and Sunde, 2009; Kluve, 2010). ${ }^{1}$ The question remains however, if this evidence is adoptable to start-up subsidies as those programs do not focus on the integration into dependent employment but into self-employment. Labor demand side restrictions in areas with relatively bad labor market conditions generally increase entries into start-up programs as job

\footnotetext{
${ }^{1}$ This is not necessarily true for subgroups of the workforce. For instance, McVicar and Podivinsky (2010) consider unemployed youths and investigate the effect of the New Deal for Young People in Britain. They find an inverse u-shaped relationship between program effectiveness and unemployment rates.
} 
offers are limited and starting an own business is an opportunity to leave unemployment. However, the survival of firms in deprived areas is also lower, such that the overall effect remains an empirical question which we aim to answer with this paper. To do so, we compare labor market outcomes of participants with those of other unemployed individuals and assess the effectiveness of start-ups subsidies as an ALMP program under different economic conditions. Furthermore, we try to disentangle whether regional effect heterogeneity is primarily driven by labor demand side restrictions or differences in business performance.

We use a combination of administrative and survey data from a large sample of participants in two distinct start-up programs in Germany, i.e. Bridging Allowance (BA) and Start-up Subsidy (SUS) as well as a control group of unemployed who did not enter these programs. We observe these individuals for five years after start-up and are able to monitor not only survival and personal income but also detailed information on the business structure. Both programs basically differ in terms of the amount and length of the subsidy payment by which different types of individuals are attracted. For instance, SUS participants are generally less qualified, have less work experience (in particular in the field of business foundation) and therefore are less likely to receive unemployment benefits and if so at lower levels than BA recipients (cf. Caliendo and Kritikos, 2010). BA participants are more similar to general business founders while SUS participants are rather "atypical". To investigate the influence of prevailing local economic conditions at business start-up on the founding process, business development and effect heterogeneity in terms of employment and income prospects of participants, we add monthly information on unemployment rates and GDP per capita at the labor agency district level. Based on the distribution of these economic indicators, we distinguish six types of regional labor markets.

The descriptive evidence shows that businesses founded by SUS and BA participants are differently affected by local economic conditions at start-up. While businesses by BA participants experience slightly larger firm survival, higher income and more job creation in favorable areas, SUS businesses experience a negative relationship between business success and economic conditions. We use propensity score matching methods and compare participants in BA and SUS with other unemployed individuals to calculate causal program effects. We find program-specific effect heterogeneity with respect to local economic conditions on employment prospects of participants. While the BA program turns out to be generally more effective in regions with disadvantaged economic conditions; we find not such a clear pattern for the case of SUS. A detailed analysis on possible mechanisms driving the effect heterogeneity reveals that estimated employment effects are primarily affected by varying labor market performance of non-participants (indicating labor demand side restrictions) and less by differences in terms of firm survival under different economic circumstances.

The paper is organized as follows: Section 2 discusses some theoretical considerations and expectations about the impact of local economic conditions on firm characteristics (start-up rates and business development) and on the effectiveness of start-up programs. Section 3 explains the institutional setting of the two start-up subsidies under scrutiny. Section 4 represents the main part of the paper and contains the empirical analysis includ- 
ing data description, descriptive evidence, and the identification strategy and results of the causal analysis. Section 5 summarizes the main findings and discusses policy conclusions.

\section{Theoretical Considerations}

The aim of this study is to investigate the effectiveness of start-up subsidy programs to improve labor market prospects of unemployed individuals under different local economic conditions. As these programs - in contrast to other ALMP programs - focus on the integration in self-employment, the effectiveness might be affected by two issues. First, the labor market success of non-participants under different local economic conditions, and second, the business development of subsidized start-ups, i.e. the performance of participants under different local economic conditions. Therefore, we provide in the following a brief discussion of theoretical expectations with respect to both dimensions.

Beside other factors such as population density, the presence of small firms or infrastructure, regional economic conditions such as aggregate demand or unemployment are a main driver determining business formation (see Reynolds, Storey, and Westhead, 1994; Hamilton, 1989; Georgellis and Wall, 2000; Kangasharju, 2000, amongst others). The labor market approach provides an explanation as it states that individuals face an occupational choice and become self-employed if the expected discounted utility of being self-employed exceeds the one of being in dependent employment (see Knight, 1921; Blanchflower and Oswald, 1998; Parker, 2009). In such a model economic conditions might push or pull individuals into self-employment as those characteristics are likely to affect the profitability of self-employment and/or the utility of paid work (Hamilton, 1986; Georgellis and Wall, 2000; Wagner and Sternberg, 2004). For instance, rising unemployment increases the risk associated with dependent employment and decreases wages, reducing the expected utility and pushing individuals into self-employment. At the same time, the profitability of self-employment might increase due to higher availability of low-cost business takeovers (higher closure rates) or stronger business promotion by the public sector in such regions. On the other hand, the pull hypothesis predicts a negative correlation between start-ups and unemployment rates. Low unemployment rates indicate high aggregate demand which increases potential income from self-employment and leads to increased firm foundation. Start-up rates might be further raised by easier availability of capital and lower risk of failure in more favorable economic conditions (Parker, 2009). However, Hamilton (1989) and Georgellis and Wall (2000) find that both the push and the pull theory apply and provide evidence that the relationship between unemployment and business formation is inversely u-shaped. This suggests that rising unemployment pushes individuals into selfemployment only in areas with initially low unemployment rates but reduces start-up rates in regions with already high unemployment rates. The authors explain this observation by missing pull factors in very depressed areas.

While there is a large literature on economic variation and business foundation, much less research exits on the impact of regional economic conditions on post entry firm performance. In general, it is assumed that more favorable economic conditions increase business survival due to higher product demand and lower interest rates (Parker, 2009). Although 
the estimated effects vary, the empirical evidence confirms this hypothesis and shows that beside firm and industry characteristics in particular macro-economic conditions (employment growth, GDP, unemployment rate) play an important role in determining post entry firm performance (see Audretsch and Mahmood, 1995; Fritsch, Brixy, and Falck, 2006; Brixy and Grotz, 2006; Falck, 2007, amongst others). Overall it seems that more favorable conditions extend firm survival, however, with particular regard to unemployment rates the effects are ambiguous. Keeble and Walker (1994) and Audretsch and Mahmood (1995) find a negative relationship between unemployment rates and business survival, while van Praag (2003) finds a positive but not significant relationship. Fritsch, Brixy, and Falck (2006) argue that unemployment rates reflect different macro-economic dimensions (economic growth, availability of workers, start-up rates out of unemployment) and depending on the individual impact of each factor the overall effect of unemployment rates on business survival might be positive or negative. ${ }^{2}$ In addition, when looking at start-ups out of unemployment we have to take into account that individuals might have a higher tendency to switch back to dependent employment if the start-up is only used as a temporary solution to exit unemployment. This might lead to higher exit rates out of self-employment for this group of individuals during an economic upswing when the number of (dependent) job opportunities increases. This would then counteract the positive correlation between economic conditions and firm survival.

Given this evidence, one might conclude that the risk of business failure is generally higher in deprived areas which would predict higher program effectiveness in privileged areas. If this is true the question arises if subsidizing business foundation among unemployed individuals in deprived areas is a sensible strategy at all or whether participants return to unemployment immediately once the subsidy expires. Clearly, this is not only a scientifically interesting but also policy-relevant question. However, program effectiveness does not solely depend on the labor market performance of program participants (survival in self-employment) but on their performance relative to non-participants in the same area. Taking this into account brings up a reverse hypothesis, namely that start-up programs might be more effective in deprived areas as self-employment provides an alternative to dependent employment which is typically limited in such regions. Existing labor demand side restrictions in deprived areas might lead to lower employment probabilities among non-participants and hence to higher program effectiveness in these areas compared to privileged areas. ${ }^{3}$ As theoretical considerations do not deliver a clear answer about which of the two opposing effects dominates, i.e., higher business survival versus higher employment probabilities among non-participants in regions with favorable economic conditions, this is an empirical question which will be examined henceforth.

\footnotetext{
${ }^{2}$ While the availability of workers to new firms predicts a clear positive impact on firm survival, the effect of economic growth and start-up rates out of unemployment is ambiguous. We refer to Fritsch, Brixy, and Falck (2006) and Falck (2007) for a detailed discussion on how economic factors might affect business survival.

${ }^{3}$ This is in line with findings by Lechner and Wunsch (2009) who show that training programs in Germany lead to larger employment effects if unemployment is high in terms of both periods and regions. The authors argue that non-participants are less likely to find a job during periods of high unemployment and if then probably worse jobs. In contrast, participants are locked into the program when unemployment is high and might face better search and economic conditions if the program elapses.
} 


\section{Institutional Settings in Germany}

In this study we investigate the effectiveness of two distinct start-up subsidies under different economic conditions. Both programs mainly differ with respect to the amount and length of the subsidy. The first program, the Bridging Allowance, amounts to the individual unemployment benefits plus a lump sum payment (68.5\% of the benefits) for social security and is paid during the first six months of self-employment. ${ }^{4}$ To receive the subsidy the unemployed have to be eligible for unemployment benefits and have an externally approved business plan (issued by the regional chamber of commerce). While the BA was introduced in 1986 already, the second program, the Start-up Subsidy was introduced as part of a bigger labor market reform in 2003. The main intention for the introduction of a second program was to encourage small business start-ups by opening the program to a larger group of unemployed individuals. Eligibility to SUS was therefore not restricted to unemployed individuals with benefit entitlement but also open to those with meanstested social assistance, i.e., primarily long-term unemployed and individuals with limited labor market experience. SUS consists of a lump-sum payment of $€ 600$ per month in the first year, $€ 360$ per month in the second and $€ 240$ per month in the third year and was prolonged on a yearly basis if self-employment income did not exceed $€ 25,000$ per year. Furthermore, SUS recipients have to pay into the statutory pension fund and can claim a reduced rate for statutory health insurance. When SUS was introduced in 2003, applicants did not have to submit business plans for prior approval, but they have been required to do so since November $2004 .^{5}$ All eligible applicants received the subsidy (by a legal entitlement) but a parallel receipt of BA and SUS was excluded.

Caliendo and Kritikos (2010) investigate the characteristics of participants in both programs and show that due to the institutional settings both programs attract a different clientele of individuals. It was rational to choose BA if unemployment benefits were fairly high or if the income generated through the start-up firm was expected to exceed $€ 25,000$ per year. Therefore, SUS participants turn out to be on average less qualified, having less work experience (in particular in the field of business foundation) and therefore are less likely to receive unemployment benefits and if they do then at lower levels than BA recipients. The authors conclude that BA participants are quite similar to general business founders and SUS participants are rather "atypical". As we will see later on, this selection process turns out to be important with respect to our results.

\footnotetext{
${ }^{4}$ On average, BA male participants in our sample received $€ 1,077$ unemployment benefits per months during their unemployment spell. Given the additional lump sum payment for social security of $68.5 \%$ this corresponds to an average BA payment of $€ 1,814$ per months.

${ }^{5}$ In practice, the burden to get such a business plan is quite low so that the impact on the quality of business start-ups is rather ambiguous. Public institutions such as the chambers of commerce and industry implemented a standardized procedure to provide individuals with such documents. However, we do not have data on subsidized business start-ups after November 2004 so that we can not empirically evaluate its impact.
} 


\section{Empirical analysis}

\subsection{Data}

The data we use consist of random samples of program entries in SUS and BA from the third quarter of 2003 in Germany (treatment group). ${ }^{6}$ As a control group, we consider other unemployed individuals from the third quarter of 2003 who were also eligible to the programs but did not participate in this particular quarter. ${ }^{7}$ The data combines administrative data from the Federal Employment Agency (FEA) with information from a telephone survey. ${ }^{8}$ The survey was conducted in three interview waves, whereby two interviews took place in January/February of 2005 and 2006 and the last interview in May/June 2008. Finally, the data contain detailed information on individual socio-demographics and labor market history before treatment, program-specific aspects, and different labor market outcomes up to five years after start-up. We restrict our analysis to individuals who participated in every interview in order to observe individual labor market outcomes for the entire period of 56 months. We focus in our analysis on men only, since start-ups by women differ in their motivation and intensity. While men are represented along the entire distribution of entrepreneurs, female entrepreneurs tend to be concentrated in particular sectors and among low-profit businesses. This can be attributed to a different motivation, e.g., because more women are seeking a work-family balance instead of earning maximization (Klapper and Parker, 2011; Boden, 1999). This also explains why women are significantly less likely to become full-time self-employed (Gurley-Calvez, Biehl, and Harper, 2009; Lechmann and Schnabel, 2012). As we are interested in the effectiveness of start-up programs to improve labor market prospects of participants, we circumvent these issues by excluding women from the analysis and avoiding side-effects due to differences driven by labor supply decisions of female participants and non-participants. ${ }^{9}$ Finally, our estimation sample sonsists of 715 male participants in SUS, 1,096 male participants in BA and 1,343 male non-participants.

To estimate regional effects, we classify regional labor markets (identified by labor agency districts in our sample) by the distribution of different economic indicators. Based on the theoretical considerations and previous empirical evidence we aggregate labor agency districts by the level of unemployment rates and GDP as these measures reflect the macro-economic conditions for dependent employment (wages, labor market tightness) and self-employment (aggregate demand, productivity) which influence the decision to start a business, its post-entry performance and reflects existing labor demand side restrictions. Therefore, we add those aggregate information on labor agency districts in the third quar-

\footnotetext{
${ }^{6}$ Having access to only one particular quarter of entrants bears the risk of a selective sample. However, comparing the distribution of certain characteristics (e.g. age and educational background) across different quarters does not show any significant differences.

${ }^{7}$ However, individuals in the control group are allowed to participate in ALMP programs afterwards. The actual number of non-participants who participated in ALMP programs after the third quarter 2003 is rather low. Approximately $29 \%$ of all non-participants were assigned to programs of ALMP and only $3 \%$ participated in SUS or BA within our observation period.

${ }^{8}$ For a more extensive discussion of data construction see Caliendo and Künn (2011).

${ }^{9}$ Caliendo and Künn (2012) provide evidence on the effectiveness of start-up programs for unemployed women by taking female-specific needs into account.
} 
ter 2003 to our data. ${ }^{10}$ The unemployment rates are obtained from the German Federal Labor Agency, and the gross domestic product from the German Federal Statistical Office. We calculate GDP per capita to take district sizes into account.

We aggregate labor agency districts by dividing the distribution of the economic measures into three parts reflecting poor, medium and good conditions. ${ }^{11}$ We note that the economic conditions are relatively stable within our observation window. ${ }^{12}$

\section{INSERT TABLE 1 HERE}

Table 1 shows the distribution of the different economic measures within the full estimation sample and within each of the six stratified subsamples. First of all, unemployment rates and GDP per capita are not perfectly correlated as they capture different economic conditions (as discussed above). The correlation coefficient is -0.509 and as a consequence, the classified subsamples (poor/medium/good) contain partly different individuals using the unemployment rate or GDP metric. For instance, the poor category using the GDP metric contains in total 1,048 individuals from which only $724(69 \%)$ are also included in the poor category using the unemployment rate. Moreover, it can be seen that we do not observe program entries for five labor market districts in Germany, so that we only observe 176 instead of 181 existing labor office districts in our data. The figures further suggest that the distribution of both measures are slightly asymmetric within the full estimation sample which is reflected by differences between mean and median, and varying numbers of assigned labor market districts within each stratified subsample. We further see that sufficient variation in terms of the measures exist to classify distinctive regional labor markets. For instance, areas characterized by poor labor market conditions show a relatively low GDP per capita with a mean of 19,203 Euro which is 14,340 Euro lower than in areas characterized by good economic conditions which is quite substantial.

\subsection{Descriptive Analysis}

Based on these observations, this Section considers variables related to the founding decision of individuals and business development in order to deliver descriptive evidence to the theoretical expectation formulated in Section 2. Note that all descriptive results presented below are adjusted for selection bias due to panel attrition by using sequential inverse probability weighting (see Wooldridge, 2002). ${ }^{13}$

\footnotetext{
${ }^{10}$ Although business formation influences economic development on the aggregate level (see Storey, 1994; Audretsch and Keilbach, 2004; Fritsch, 2008), the prevailing local economic conditions are assumed to be exogenous to new entries into self-employment.

${ }^{11}$ We additionally stratify the sample by dividing the respective distributions into four equal parts. Results are similar and lead to the same conclusion. However, lower numbers of observation in each cell result in poor matching quality why we decided to take three categories as the preferred strategy.

${ }^{12}$ We also categorized the sample based on the distribution of unemployment rates and GDP measured at the end of our observation window, i.e., May/June 2008, and compared it to initial categorization. We find $82 \%$ of individuals assigned to the same category in terms of unemployment rates and $95 \%$ in terms of GDP per capita.

${ }^{13}$ The willingness of individuals to participate in the survey decreased over time. On average, we observe $46 \%$ of all participants and $37 \%$ of all non-participants for the entire period of 56 months. The attrition induced a positive selection, i.e., individuals who perform relatively well in terms of labor market outcomes
} 


\subsubsection{Description of the founding process}

As derived from an occupational choice model, theory does not unambiguously predict how different economic conditions influence self-employment rates as both push or pull motives might be valid such that empirical evidence is needed. To identify the motivation of individuals in our estimation sample, we depict the distribution of push and pull motives conditional on prevailing local economic conditions at start-up in Table 2. First of all, we see that SUS participants are generally more likely to be pushed into self-employment while BA participants are slightly more often motivated by pull items. On average, $84 \%$ $(53 \%)$ of SUS participants report the item "Termination of unemployment" ("I always wanted to be my own boss") as the motivation to start a business compared to $76 \%$ (56\%) in the case of BA. This is consistent with the program-specific selection pattern, i.e., BA participants are more similar to general business founders while SUS are rather atypical business founders. It is also consistent with earlier research by Caliendo and Kritikos (2009) showing that the previous stereotype suggesting that all start-ups by unemployed persons are necessity based does not hold.

The hypothesis that necessity (opportunity) start-ups are overrepresented (underrepresented) in areas with rather poor economic conditions can not be clearly confirmed by Table 2. While we do see, that the push motive "Termination of unemployment" has its highest shares mostly in regions with poor economic conditions, the evidence for the pull motive "I always wanted to be my own boss" is more mixed. This could indicate that pull motives are less influenced by local economic conditions while push motives are more affected. However, since the overall differences between the regions are quite small, such an interpretation needs to be made with caution.

\section{INSERT TABLE 2 HERE}

Moreover, Table 2 shows that the subsidized business founders out of unemployment tend to invest less at start-up in areas with unfavorable economic conditions. This confirms the finding from above that unemployed individuals are likely to be pulled (pushed) into self-employment if labor market conditions are (un)favorable. Again, the evidence is less clear for the stratified sample by GDP per capita.

\subsubsection{Labor market integration and business development}

Following theoretical considerations about the influence of economic conditions on business development as well as existing evidence, we would expect higher business survival and growth in areas characterized by favorable economic conditions. However, we have to keep in mind that we consider start-ups out of unemployment for which improved economic conditions might partly lead to lower business survival if there is a higher tendency to switch back to dependent employment with increased job opportunities (as discussed in Section 2). This might counteract the positive correlation between economic conditions

are more likely to respond. Therefore, we use sequential inverse probability weighting to adjust for selective attrition. However, the causal analysis relies on unweighted outcome variables as participants and nonparticipants are similarly affected by selection due to panel attrition. 
and firm survival. To empirically assess the long-term labor market success of former participants in both programs as well as business growth, we depict different indicators in Table 3 measured 56 months after start-up.

\section{INSERT TABLE 3 HERE}

Considering the labor market status of former program participants 56 months after start-up, we see that in case of SUS (BA) about $60 \%$ (70\%) are still self-employed and approximately $20 \%$ are in dependent employment. This indicates a high and persistent integration into employment. The higher shares in self-employment in case of BA might be explained by the already mentioned selection of individuals into both programs, where the positive selection of individuals in BA probably increases the probability of surviving in self-employment.

However, we hardly detect large differences in terms of shares in self-employment across areas. It can be seen that the shares in self-employment are slightly higher if labor market conditions (reflected by unemployment rates) are rather unfavorable which suggests that missing job opportunities might increase the probability to remain self-employed. With respect to dependent employment we do not find such a clear pattern. For instance, in the case of SUS we find higher shares in dependent employment if labor market conditions are unfavorable and the reverse for the case of BA.

\section{INSERT FIGURE 1 HERE}

To further assess the influence of prevailing local economic conditions at start-up on business survival, we additionally provide Kaplan-Meier estimates for the survival probability in the first self-employment spell across the stratified subsamples in Figure 1. Besides the visual illustration we additionally report a Cox regression-based test on the equality of survival curves below each Figure (see Suciu, Lemeshow, and Moeschberger, 2004). This test compares observed and expected exit probabilities in each regional subgroup, where the expected exit probabilities are calculated under the null hypothesis that the survival curves are the same across those groups. Consistent with the selection into the two programs, Figure 1 suggests that more favorable economic conditions at the time of start-up slightly extend firm survival for the case of BA. In the case of SUS we find the reverse relationship, i.e., higher firm survival in deprived areas. This suggests that limited job opportunities in areas characterized by deprived economic conditions probably urge SUS participants to remain self-employed. However, the statistical support is not very strong (only significant in two out of four cases using a critical value of 0.05) which leads to the conclusion that survival of subsidized businesses is only partly affected by local economic conditions at the time of business start-up. ${ }^{14}$

With respect to income, Table 3 shows the individual monthly working income of former participants 56 months after start-up. We find a clear positive correlation between

\footnotetext{
${ }^{14}$ This is in line with findings by Tokila (2009) who runs a survival analysis on subsidized start-ups out of unemployment in Finland. She finds that regional characteristics have only a minor impact on the exit rate.
} 
income and prevailing local economic conditions at start-up for the case of BA. For instance, the working income is higher in areas characterized by good economic conditions (low unemployment rates and high GDP) but the evidence is less clear-cut for the participants in SUS.

Finally, we consider business size in terms of the employee structure. Recalling the discussion in Section 2 we would expect that more favorable economic conditions facilitate business development. We depict the employee structure in Table 3 by the share with at least one employee and conditional on having at least one employee the resulting absolute number of employees. With respect to business growth we report the \%-change in terms of the number of employees compared to the first interview which took place 16 months after start-up. First of all, we can see for the case of BA that the share of firms with at least one employee as well as the absolute number of employees is larger if the firm started under favorable economic conditions. This is in line with the theoretical expectations. However and consistent with the findings regarding business survival, we find for the case of SUS the reverse relationship, i.e., former SUS recipients create less employment if founded in deprived areas. Looking at business growth from month 16 to month 56, we see that firms indeed experience employment growth (except SUS recipients in areas with low unemployment rates) but we do not find a clear pattern with respect to the local economic conditions at the time of business start-up. For instance, former SUS recipients who founded a business in areas characterized by poor/medium/good economic conditions based on unemployment rates experience an employment growth of 41\%/36\%/-10\%. This indicates higher employment growth in deprived areas. However, conditioning on GDP per capita we observe the opposite, i.e., higher employment growth in privileged areas.

In summary, we conclude from the descriptive evidence that businesses founded by SUS and BA participants are differently affected by prevailing local economic conditions. While businesses by BA participants experience slightly higher firm survival, larger income and more job creation in favorable areas, SUS businesses experience a negative relationship between business success and economic conditions at start-up. Therefore, it seems that the theoretical expectation that favorable economic conditions facilitate business development is only adoptable to BA participants but not to SUS participants. This might be explained by the positive selection of individuals in the two programs, with BA participants being more similar to general business founders.

\subsection{Causal Analysis and Implementation}

\subsubsection{Identification Strategy}

In order to estimate causal effects, we base our analysis on the potential outcome framework, also known as the Roy (1951) - Rubin (1974) model. The two potential outcomes are $Y^{1}$ (individual receives treatment, $D=1$ ) and $Y^{0}$ (individual does not receive treatment, $D=0$ ) whereby the observed outcome for any individual $i$ can be written as $Y_{i}=Y_{i}^{1} \cdot D_{i}+\left(1-D_{i}\right) \cdot Y_{i}^{0}$. As the treatment effect for each individual $i$ is then defined as $\tau_{i}=Y_{i}^{1}-Y_{i}^{0}$ and both potential outcomes are never observed for the same individual at the same time (referred to as the fundamental evaluation problem), we focus on the 
most prominent evaluation parameter, which is the average treatment effect on the treated (ATT):

$$
\tau_{A T T}=E\left(Y^{1} \mid D=1\right)-E\left(Y^{0} \mid D=1\right) .
$$

The last term on the right hand side of equation (1) describes the hypothetical outcome without treatment for those individuals who received treatment. Since the condition $E\left(Y^{0} \mid D=1\right)=E\left(Y^{0} \mid D=0\right)$ is usually not satisfied with non-experimental data, estimating ATT by the difference in sub-population means of participants $E\left(Y^{1} \mid D=1\right)$ and non-participants $E\left(Y^{0} \mid D=0\right)$ will lead to a selection bias as participants and non-participants are likely to be selected groups in terms of observable and unobservable characteristics with different outcomes, even in the absence of the program. ${ }^{15}$ We apply propensity score matching and thus rely on the conditional independence assumption (CIA), which states that conditional on observable characteristics $(W)$ the counterfactual outcome is independent of treatment $Y^{0} \amalg D \mid W$, where $\amalg$ denotes independence. In addition to the CIA, we also assume overlap $\operatorname{Pr}(D=1 \mid W)<1$, for all $W$ which implies that there are no perfect predictors which determine participation. These assumptions are sufficient for identification of the ATT based on matching (MAT), which can then be written as:

$$
\tau_{A T T}^{M A T}=E\left(Y^{1} \mid W, D=1\right)-E_{W}\left[E\left(Y^{0} \mid W, D=0\right) \mid D=1\right],
$$

where the first term can be directly estimated from the treatment group and the second term from the matched comparison group. The outer expectation is taken over the distribution of $W$ in the treatment group.

As direct matching on $W$ can become hazardous when $W$ is of high dimension ("curse of dimensionality"), Rosenbaum and Rubin (1983) suggest using balancing scores $b(W)$ instead. These are functions of the relevant observed covariates $W$ such that the conditional distribution of $W$ given $b(W)$ is independent of the assignment to treatment, that is, $W \amalg D \mid b(W)$. The propensity score $P(W)$, i.e., the probability of participating in a program, is one possible balancing score. For participants and non-participants with the same balancing score, the distributions of the covariates $W$ are the same, i.e., they are balanced across the groups. Hence, the identifying assumption can be re-written as $Y^{0} \amalg D \mid P(W)$ and the new overlap condition is given by $\operatorname{Pr}(D=1 \mid P(W))<1$.

The CIA is clearly a very strong assumption and its justification depends crucially on the availability of informative data which allow to control for all relevant variables that simultaneously influence the participation decision and the outcome variable. Economic theory, a sound knowledge of previous research, and information about the institutional setting should guide the researcher in specifying the model (see, e.g., Smith and Todd, 2005 or Sianesi, 2004). Although there is no common rule on the set of information necessary, Lechner and Wunsch (2013) identify personal and firm characteristics of previous employment as well as labor market history, detailed information on the current unemployment spell and regional characteristics to be most important to include when estimating

\footnotetext{
${ }^{15}$ See, for example Caliendo and Hujer (2006) for further discussion.
} 
program effects of ALMP. We have both administrative and survey information available that allows us to mostly reproduce the set of information as suggested by Lechner and Wunsch (2013). In addition we include information on parental self-employment as intergenerational transmission has been shown to significantly influence the start-up decision (see Caliendo and Künn, 2011). Although the justification of the CIA is not directly testable with non-experimental data, we argue that having these informative data makes the CIA likely to hold in our application. Nevertheless, we test the robustness of our results with respect to unobserved heterogeneity in two directions. First, we implement a conditional difference-in-differences (DID) estimator to control for time-invariant unobserved differences between participants and non-participants (see Heckman, Ichimura, Smith, and Todd, 1998). Second, we use a bounding approach as suggested by Rosenbaum (2002) which introduces an artificial term in the selection equation and tests to which extent of this unobserved factor the results remain significant. Note, that this approach does not answer the question whether or not the CIA is fulfilled but conveys information on the robustness of the results with respect to unobserved heterogeneity. Applying both tests, the results turn out to be robust with respect to unobserved heterogeneity suggesting that the CIA is a reliable assumption in our study. ${ }^{16}$

Moreover, for identification of causal effects, any general equilibrium effects need to be excluded, that is treatment participation of one individual can not have an impact on outcomes of other individuals. This assumption is referred to as stable-unit-treatmentvalue-assumption (SUTVA). Imbens and Wooldridge (2009) argue that the validity of such an assumption depends on the scope of the program as well as on resulting effects. They infer that for the majority of labor market programs, the SUTVA is potentially fulfilled because such programs are usually of small scope with rather limited effects on the individual level. We follow their argumentation and refer to the absolute number entries into SUS and BA which is approximately of the same scope as other ALMP programs and in relation to the total number of entries into unemployment of 7.6 million in 2003 quite small. ${ }^{17}$

\subsubsection{Estimation of treatment propensity}

To estimate causal effects of participation in SUS and BA on labor market outcomes of participants, we first of all estimate the propensity scores (PS) of program participation by applying a non-linear probit-estimation. We take variations in terms of the selection into treatment due to different economic conditions into account and estimate the PS within each stratified labor market conditional on unemployment rates and GDP per capita separately, i.e. $P_{L M}(W)=\operatorname{Pr}(D=1 \mid W, L M=j)$ where $D$ is the treatment indicator, $W$ are observed covariates and $L M$ denotes the six different labor markets $(j=1, \ldots, 6)$ characterized by poor, medium and good economic conditions based on unemployment rates and GDP per capita. The informative data at hand allows the inclusion of individ-

\footnotetext{
${ }^{16}$ We only state the main findings of the robustness tests here. Detailed results are available on request from the authors.

${ }^{17}$ In 2003, 254 thousand individuals participated in SUS or BA compared to 183 (295) thousand entries in wage subsidies (vocational training) in Germany.
} 
ual information on socio-demographics, education, past employment, working experience, income situation as well as regional information in the propensity scores estimation. We test different specifications following economic theory and previous empirical findings as outlined above. In addition we check econometric indicators such as significance of parameters or pseudo- $R^{2}$ to finally determine one preferred specification. ${ }^{18}$ Results of the probit-estimation are depicted in Tables A.1 to A.4 in the Appendix.

As expected from theoretical considerations and descriptive evidence, we find varying selection patterns into programs conditional on prevailing local economic conditions. For instance, comparing the coefficients of the PS estimations for the BA program in areas characterized by poor and good economic conditions based on GDP per capita reveals that nearly one third of the coefficients show different signs. This confirms the hypothesis that local economic conditions affect the selection of unemployed individuals into startup programs. As each propensity score estimation contains individual selection patterns and the discussion is beyond the scope of this paper, we focus on two interesting and common findings with regard to the selection process. First, in particular individuals with an entrepreneurial family background are likely to start a business in deprived areas. This is consistent with findings by Tervo (2006) who argues that those individuals are more likely to be pushed into self-employment as they possess latent entrepreneurial human capital. Second, the higher the remaining individual unemployment benefit entitlement the less likely to start a business in areas characterized by favorable economic conditions as opportunity costs are higher (e.g. higher expected wages). Individuals remain longer unemployed and search for better jobs if the labor market offers adequate job opportunities which is more likely under favorable economic conditions.

Figures A.1 and A.2 in the Appendix show the distribution of the estimated propensity scores for all regions and both programs. It can be seen, that the distribution of the propensity scores are biased towards the tails, that is participants have a higher average probability to become self-employed than non-participants. Nevertheless, participant's and non-participant's propensity score distributions overlap to a large extent, such that we only loose very few treated observations due to the minima-maxima common support condition (see numbers below each graph).

\subsubsection{Details on matching procedure}

Based on the estimated propensity scores, we apply kernel matching and estimate the ATT as depicted in Equation 2 for each stratified labor market separately, that is $\tau_{A T T}^{M A T}$ | $L M=j, \quad j=1, \ldots, 6$. We assess the resulting matching quality, i.e., whether the matching procedure sufficiently balances the distribution of observable characteristics between participants and non-participants, within each stratified subsample with different criteria. Tables A.5 and A.6 in the Appendix present results from a simple comparison of means ( $t$-test), the mean standardized bias (MSB) and the Pseudo- $\mathrm{R}^{2}$ of the probit-estimation in the matched and unmatched sample respectively. ${ }^{19}$ While the t-test on equal means and

\footnotetext{
${ }^{18}$ For a more extensive discussion on the estimation of propensity scores, we refer to Heckman, Ichimura, Smith, and Todd (1998) and Caliendo and Kopeinig (2008) among others.

${ }^{19}$ See Caliendo and Kopeinig (2008) for a more detailed discussion of matching quality issues.
} 
the Pseudo $\mathrm{R}^{2}$ indicate towards a successful matching for both programs, the mean standard bias for SUS is after matching within some cells still above the critical value of $5 \%$ as suggested by Caliendo and Kopeinig (2008). However, the remaining bias after matching does not have a substantial influence on the selection into treatment (very low Pseudo- $\mathrm{R}^{2}$ ), so that we conclude that the PS matching procedure sufficiently created a control group within each subsample that is very similar to the respective treatment group at the point of entry into treatment. Additionally, we test if the matching procedure sufficiently balances differences between both groups in terms of pre-treatment outcome variables such as months in employment and average income in the year before program entry. The results can be found in Table A.7 in the Appendix and show no significant differences for almost all variables after matching took place (indicated by p-values $>0.05$ in column six). This reinforces the success of the matching procedure in removing pre-treatment differences between participants and non-participants.

\subsection{Results}

We assess the effectiveness of the two programs to improve labor market prospects of participants with respect to two labor market outcomes: integration into the first labor market and earnings. To measure the integration into the first labor market, we employ "self-employed or regular employed" as a binary outcome variable which is one for individuals who are either employed subject to social security contribution or self-employed and zero otherwise. We use this variable (and not survival in self-employment) for two reasons: First, non-participants are less likely to become self-employed than participants; and hence, comparing participants and non-participants with respect to self-employment only would bias the causal effects upwards. Second, as the main objective of ALMP is to integrate individuals into the first labor market, this justifies categorizing being regular employed as a success (even if it means that the self-employment spell was terminated). It should be clear that the definition of this outcome variable does not imply that selfemployment and wage employment are equally desirable from a program perspective but it is rather an appropriate measure that reflects the degree of labor market integration within both the treatment and control group. As a second outcome variable we assess the impact on individual monthly working income. Table 4 contains a summary of the estimated ATT for defined outcome variables within each stratified labor market. The employment effects are depicted at different points in time and cumulated over the entire observation period of 56 months. Since we do not have longitudinal information about income, the income effects in Table 4 refer to the end of our observation period.

\section{INSERT TABLE 4 HERE}

First of all, it is visible that both programs lead to throughout positive and significant employment effects. Program participation significantly increases the employment probability of participants compared to non-participants. We also find positive effects on working income, although they are not always statistically significant. Therefore, independent of the effect heterogeneity with respect to local economic conditions (as will be shown below) both start-up subsidies are effective ALMP tools. 
Now, taking a closer look at the employment effects, we detect some program-specific patterns: For the case of BA the results suggest that it is more effective in disadvantaged areas as indicated by increasing employment effects with decreasing local economic conditions. For instance, the total cumulated employment effect within regions characterized by poor economic conditions based on unemployment rates (GDP) is 20.7 (19.8) months for BA but amounts to only 14.6 (14.2) months in regions with good economic conditions. We do not detect such a clear pattern in the case of SUS. Conditioning on unemployment rates, employment effects tend to be slightly higher in areas characterized by poor economic conditions. Although this pattern is much weaker, it is still consistent with the pattern for the BA program. However, based on the GDP per capita comparison, the employment effects turn out to be higher in areas characterized by good economic conditions, and lower in areas characterized by poor conditions. ${ }^{20}$ This is opposite to the finding for the BA program. We highlight though that the differences in point estimates are much smaller for the SUS than BA program.

To further investigate the mechanism behind the program-specific pattern, Figure A.3 in the Appendix shows corresponding employment probability levels among treated and matched control individuals over time. As the ATT in Table 4 depicts the difference between participants and matched non-participants, Figure A.3 reveals one possible explanation for the effect heterogeneity. The varying employment effects are primarily attributable to the labor market performance among the non-participants under different economic conditions. While the black lines (treated within different regions) almost overlap, the gray lines (matched controls within different regions) show partly substantial differences. For the case of $\mathrm{BA}$, it is visible that non-participants in disadvantaged regions face lower employment probabilities than in privileged regions leading to the clear pattern, that programs are more effective in disadvantaged areas. It seems that BA with its integration into self-employment counteract the limited job opportunities for these groups (higher educated with higher earnings in the past) in disadvantaged areas. Again, for SUS we do not find such a clear pattern. It can be seen that non-participants in areas characterized by poor economic conditions (solid gray lines) face on average no clear disadvantage in terms of employment probabilities compared to non-participants in other areas. However, we can see for both programs that effect heterogeneity is primarily driven by labor market performance of non-participants.

\section{INSERT FIGURE 2 HERE}

Figure 2 illustrates this negative relationship between labor market performance of matched non-participants and program effectiveness graphically. Therefore we scatter the ATT for the total cumulated employment outcome (x-axis) against the estimated counterfactual outcome (y-axis) which reflects the labor market performance of matched nonparticipants. We clearly see for both programs that the lower the counterfactual outcome (probably due to limited job opportunities in the labor market) the higher the ATT. This

\footnotetext{
${ }^{20}$ Keep in mind that unemployment rates and GDP are not perfectly correlated so that the subsamples (poor/medium/good) contain partly different individuals using the unemployment rate or GDP metric (see Section 4.1). This explains the slightly different results.
} 
supports the hypothesis that employment effects are primarily driven by the labor market performance of non-participants under different economic conditions and less by differences in terms of firm survival. This is in line with the Kaplan-Meier estimates in Section 4.2 .2 , which have shown that survival of subsidized businesses is only partly significantly affected by economic conditions at the time of business start-up.

\section{Conclusion}

In this paper we study the effectiveness of two different start-up subsidies for unemployed individuals in Germany under different economic conditions. To do so, we compare labor market outcomes of program participants with those of other unemployed individuals in order to assess in which areas start-up programs are particularly effective. Moreover, we investigate the influence of local economic conditions at the time of start-up on the founding process and development of businesses over time. We use a combination of administrative and survey data from a large sample of participants in two distinct programs, i.e. Bridging Allowance (BA) and Start-up Subsidy (SUS) as well as a control group of unemployed who did not enter these programs. This data is enriched with aggregate information on unemployment rates and GDP per capita at the labor agency district level to distinguish six types of regional labor markets.

The descriptive evidence shows that subsidized business founders located in regions with rather favorable economic conditions are more likely to be pulled into self-employment and invest more capital at start-up. With respect to business development a programspecific pattern arises. While businesses by BA participants experience slightly longer firm survival, higher income and more job creation in favorable areas, SUS businesses experience a negative relationship between business success and economic conditions. This suggests that limited job opportunities in areas characterized by deprived economic conditions probably urge SUS participants to remain self-employed. It seems that the theoretical expectation that favorable economic conditions facilitate business development is only adoptable to BA participants but not to SUS participants. This might be explained by the selection of individuals in the two programs, where BA participants are quite similar to general business founders while SUS participants are rather atypical.

Based on propensity score matching methods to calculate causal program effects, we find that both programs are effective policy tools and increase prospective employment probabilities and working income (although not always statistically significant) of participants. We further show program-specific effect heterogeneity with respect to local economic conditions. This regional effect heterogeneity has not been examined so far and shows that the BA program turns out to be generally more effective in regions with disadvantaged economic conditions. For participants in SUS we find a much weaker pattern conditional on unemployment rates and an opposite relationship between program effectiveness and local economic conditions based on GDP per capita. A detailed analysis on possible mechanisms driving this regional effect heterogeneity reveals that estimated employment effects are primarily affected by varying labor market performance of non-participants (indicating labor demand side restrictions) and less by differences in terms of firm survival under 
different economic circumstances.

Overall, our results confirm the promising evidence on the effectiveness of start-up programs to improve employment and income prospects of participants. It has often been argued that these programs are especially successful as they provide an alternative to limited job offers in the labor market. In this regard, Caliendo and Künn (2011) show that both start-up programs - SUS and BA - are particularly effective for disadvantaged groups in the labor market such as low educated or young individuals who generally face limited job offers. Our results now add the insight that SUS and BA are also effective under different economic conditions, whereby the degree of effectiveness primarily depends on the labor market performance of non-participants which reflects labor market tightness within different regions. This supports the hypothesis that start-up programs are a promising tool to augment traditional ALMP programs as they depict an alternative to existing labor demand side restrictions across subgroups and regions.

Finally, we want to emphasize some policy conclusions and limitations of our study. From an ALMP perspective, the study shows that providing unemployed individuals the possibility to become self-employed (and hence escape unemployment) by offering the two programs has been a successful strategy. It effectively helped participants to overcome labor demand restrictions and to integrate them in the labor market in the long-run. Policy makers should therefore continue this strategy and provide such programs to unemployed individuals in the future. However, at the same time policy makers should be cautious in expanding the scale of such start-up programs programs (e.g., by increasing the amount/duration of the subsidy or lowering the entry criteria) due to three reasons: First, this might attract lower ability individuals who would actually not become selfemployed under the current circumstances which might reduce the overall effectiveness of the programs. Second, subsidy programs are relatively costly and bear the risk of deadweight effects, i.e., nascent entrepreneurs intentionally register unemployed to receive the subsidy. Third, although we find slightly better business performance in good areas (at least for the BA program), we cannot make a causal statement if subsidized start-ups out of unemployment are successful businesses yet. To make such a statement we would need to compare program participants to other business start-ups out of non-unemployment. Unfortunately this is not possible with our data at hand. However, this is an important question and future research should provide evidence on the empirical relevance of these three concerns.

Finally, we want to emphasize some policy conclusions and limitations of our study. From an ALMP perspective, the study shows that providing unemployed individuals the possibility to become self-employed (and hence escape unemployment) by offering the two programs has been a successful strategy. It effectively helped participants (especially in areas with poor economic conditions) to overcome labor demand restrictions and to integrate them in the labor market in the long-run. Policy makers should therefore continue this strategy and provide such programs to unemployed individuals in the future. To further increase the effectiveness of the programs, it might be worth thinking about the provision of accompanying counseling or coaching programs which have been proven to be effective (see, e.g., Rotger, Gortz, and Storey, 2012). However, policy makers should be cautious in 
expanding the scale of such start-up programs (e.g., by increasing the amount/duration of the subsidy or lowering the entry criteria) due to three reasons: First, this might attract lower ability individuals who would actually not become self-employed under the current circumstances which might reduce the overall effectiveness of the programs. Second, subsidy programs are relatively costly and bear the risk of deadweight effects, i.e., nascent entrepreneurs intentionally register unemployed to receive the subsidy. Third, although we find slightly better business performance in good areas (at least for the BA program), we cannot make a causal statement if subsidized start-ups out of unemployment are successful businesses yet. To make such a statement we would need to compare program participants to other business start-ups out of non-unemployment. Unfortunately this is not possible with our data at hand. However, this is an important question and future research should provide evidence on the empirical relevance of these three concerns. 


\section{References}

Audretsch, D., And M. Keilbach (2004): "Entrepreneurship Capital and Economic Performance," Regional Studies, 38, 949-959.

Audretsch, D., and T. Mahmood (1995): "New Firm Survival: New Results Using a Hazard Function," The Review of Economics and Statistics, 77(1), 97-103.

Blanchflower, D., AND A. Oswald (1998): "What Makes an Entrepreneur?," Journal of Labor Economics, 16, 26-60.

Boden, R. J. (1999): "Flexible Working Hours, Family Responsibilities, and Female SelfEmployment: Gender Differences in Self-Employment Selection," American Journal of Economics and Sociology, 58(1), 71-83.

Brixy, U., and R. Grotz (2006): "Regional Patterns and Determinants of New Firm Formation and Survival in Western Germany," Discussion Paper 5/2006, IAB.

Caliendo, M., and R. Hujer (2006): "The Microeconometric Estimation of Treatment Effects - An Overview," Allgemeines Statistisches Archiv, 90(1), 197-212.

Caliendo, M., and S. Kopeinig (2008): "Some Practical Guidance for the Implementation of Propensity Score Matching," Journal of Economic Surveys, 22(1), 31-72.

Caliendo, M., and A. Kritikos (2009): "I Want to, But I Also Need to": Start-Ups Resulting from Opportunity and Necessity," Discussion Paper 4661, IZA.

Caliendo, M., and A. Kritikos (2010): "Start-Ups by the Unemployed: Characteristics, Survival and Direct Employment Effects," Small Business Economics, 35(1), 71-92.

Caliendo, M., and S. Künn (2011): "Start-Up Subsidies for the Unemployed: LongTerm Evidence and Effect Heterogeneity," Journal of Public Economics, 95(3-4), 311331.

(2012): "Getting Back into the Labor Market: The Effects of Start-Up Subsidies for Unemployed Females," Discussion Paper 6830, IZA.

DAR, A., AND I. S. GILl (1998): "Evaluationg Retraining Programs in OECD Countries: Lessons Learned," The World Bank Research Observer, 13(1), 79-101.

Dar, A., and Z. Tzannatos (1999): "Active Labor Market Programs: A Review of the Evidence from Evaluations," SP Discussion Paper 9901, The World Bank.

Fahr, R., And U. Sunde (2009): "Did the Hartz Reforms Speed-Up the Matching Process? A Macro-Evaluation Using Empirical Matching Functions," German Economic Review, 10(3), 284-316.

FALCK, O. (2007): "Survival Chances of New Businesses: Do Regional Conditions Matter?," Applied Economics, 39, 2039-2048.

FAY, R. (1996): "Enhancing the Effectiveness of Active Labor Market Policies: Evidence from Programme Evaluations in OECD Countries," Labour Market and Social Policy Occasional Papers 18, OECD.

Fritsch, M. (2008): "How does New Business Development Affect Regional Development? Introduction to the Special Issue," Small Business Economics, 30, 1-14.

Fritsch, M., U. Brixy, and O. Falck (2006): "The Effect of Industry, Region and Time on New Business Survival - A Multi-Dimensional Analysis," Review of Industrial Organization, 28, 285-306. 
Georgellis, Y., And H. J. Wall (2000): "What Makes a Region Entrepreneurial? Evidence from Britain," The Annals of Regional Science, 34(3), 385-403.

Gurley-Calvez, T., A. Biehl, and K. Harper (2009): "Time-Use Patterns and Women Entrepreneurs," American Economic Review: Papers and Proceedings, 99(2), 139-144.

Hamilton, R. T. (1986): "The Influence of Unemployment on the level and Rate of Company Formation in Scotland, 1950-184," Environment and Planning A, 18, 14011404 .

(1989): "Unemployment and Business Formation Rates: Reconciling Time-Series and Cross-Section Evidence," Environment and Planning A, 21, 249-255.

Heckman, J., H. Ichimura, J. Smith, and P. Todd (1998): "Characterizing Selection Bias Using Experimental Data," Econometrica, 66(5), 1017-1098.

Imbens, G., And J. M. Wooldridge (2009): "Recent Developments in the Econometrics of Program Evaluation," Journal of Economic Literature, 47(1), 5-86.

Kangasharju, A. (2000): "Regional Variations in Firm Formation: Panel and CrossSection Data Evidence from Finland," Papers in Regional Science, 79, 355-373.

Keeble, D., And S. Walker (1994): "New Firms, Small Firms and Dead Firms: Spatial Patterns and Determinants in the United Kingdom," Regional Studies, 28(4), 411-427.

Klapper, L. F., and S. C. PArker (2011): "Gender and the Business Environment for New Firm Creation," The World Bank Research Observer, 26(2).

Kluve, J. (2010): "The Effectiveness of European Active Labor Market Programs," Labour Economics, 16(6), 904-918.

Kluve, J., And C. M. Schmidt (2002): "Can Training and Employment Subsidies Combat European Unemploment?," Economic Policy, 17(35), 409-448.

Knight, F. H. (1921): Risk, Uncertainty, and Profit. Prentice Hall.

Lechmann, D., And C. Schnabel (2012): "Why is there a gender earnings gap in selfemployment? A decomposition analysis with German data," IZA Journal of European Labor Studies, 1(6).

Lechner, M., and C. Wunsch (2009): "Are Training Programs More Effective When Unemployment is High?," Journal of Labor Economics, 27(4), 653-692.

(2013): "Sensitivity of Matching-Based Program Evaluations to the Availability of Control Variables," forthcoming in: Labour Economics.

Martin, P., And D. GrubB (2001): "What Works and for Whom: A Review of OECD Countries Experiences with Active Labour Market Policies," Swedish Economic Policy Review, 8, 9-56.

McVicar, D., And J. M. Podivinsky (2010): "Are Active Labour Market Programmes Least Effective Where They Are Most Needed? The Case of the British New Deal for Young People," Working Paper 16/10, Melbourne Institute of Applied Economic and Social Affairs.

Meager, N. (1996): "From Unemployement to Self-employement: Labour Market Policies for Business Start-up," in International Handbook of Labour Market Policy and Evaluation, ed. by G. Schmidt, J. O'Reilly, and K. Schömann, pp. 489-519. Edward Elgar. 
PARker, S. C. (2009): The Economics of Entrepreneurship. Cambridge University Press, New York, Cambridge.

Perry, G. (2006): "Are Business Start-Up Subsidies Effective for the Unemployed: Evaluation of Enterprise Allowance," Working paper, Auckland University of Technology.

Reynolds, P., D. Storey, and P. Westhead (1994): "Cross-National Comparisons of the Variation in New Firm Formation Rates: An Editorial Overview," Regional Studies, $28(4), 343-346$.

Rosenbaum, P., and D. Rubin (1983): "The Central Role of the Propensity Score in Observational Studies for Causal Effects," Biometrika, 70(1), 41-50.

Rosenbaum, P. R. (2002): Observational Studies. Springer, New York.

Rotger, G. P., M. Gortz, and D. J. Storey (2012): "Assessing the effectiveness of guided preparation for new venture creation and performance: Theory and practice," Journal of Business Venturing, 27, 50-521.

Roy, A. (1951): "Some Thoughts on the Distribution of Earnings," Oxford Economic Papers, 3(2), 135-145.

Rubin, D. (1974): "Estimating Causal Effects of Treatments in Randomised and Nonrandomised Studies," Journal of Educational Psychology, 66, 688-701.

Shane, S. (2003): A General Theory of Entrepreneurship: The Individual-Opportunity Nexus. Edward Elgar, Cheltenham (UK), Northhampton (MA, USA).

SiAnesi, B. (2004): "An Evaluation of the Swedish System of Active Labour Market Programmes in the 1990s," The Review of Economics and Statistics, 86(1), 133-155.

Smith, J., And P. Todd (2005): "Does Matching Overcome LaLonde's Critique of Nonexperimental Estimators?," Journal of Econometrics, 125(1-2), 305-353.

Storey, D. (1994): Understanding the Small Business Sector. Routledge, London.

Suciu, G. P., S. Lemeshow, and M. Moeschberger (2004): "Statistical Tests of the Equality of Survival Curves: Reconsidering the Options," in Handbook of Statistics, ed. by N. Balakrishnan, and C. R. Rao, vol. 23. North-Holland.

Tervo, H. (2006): "Regional Unemployment, Self-employment and Family Background," Applied Economics, 38, 1055-1062.

TokilA, A. (2009): "Start-Up Grants and Self-Employment Duration," Working Paper, School of Business and Economics, University of Jyväskylä.

van PraAg, C. M. (2003): "Business Survival and Success of Young Small Business Owners," Small Business Economics, 21(1), 1-17.

Wagner, J., And R. Sternberg (2004): "Start-Up Activities, Individual Characteristics, and the Regional Milieu: Lessons for Entrepreneurship Support Policies from German Micro Data," The Annals of Regional Science, 38, 219-240.

Wooldridge, J. M. (2002): Econometric Analysis of Cross Section and Panel Data. The MIT Press. 


\section{Tables and Figures}

Table 1: Distribution of labor market indicators within the estimation sample

\begin{tabular}{|c|c|c|c|c|}
\hline & \multirow[t]{2}{*}{$\begin{array}{c}\text { Full } \\
\text { sample }\end{array}$} & \multicolumn{3}{|c|}{$\begin{array}{l}\text { Aggregation of labor agency districts } \\
\text { conditional on local economic condition }\end{array}$} \\
\hline & & Poor & Medium & Good \\
\hline \multicolumn{5}{|l|}{ Unemployment rate (in \%) } \\
\hline Number of labor agency districts & 176 & 40 & 61 & 75 \\
\hline Number of individuals & 3,154 & 1,019 & 1,073 & 1,062 \\
\hline Start-up Subsidy & 715 & 237 & 251 & 227 \\
\hline Bridging Allowance & 1,096 & 337 & 361 & 398 \\
\hline Non-participants & 1,343 & 445 & 461 & 437 \\
\hline Mean & 11.292 & 17.800 & 9.690 & 6.580 \\
\hline Standard deviation & 4.995 & 2.520 & 1.150 & 0.939 \\
\hline Median & 9.383 & 17.974 & 9.383 & 6.712 \\
\hline Minimum & 4.083 & 13.193 & 7.907 & 4.083 \\
\hline Maximum & 24.584 & 24.584 & 11.862 & 7.885 \\
\hline \multicolumn{5}{|c|}{ Gross Domestic Product per capita $^{a)}$ (in thousand Euro) } \\
\hline Number of labor agency districts & 176 & 58 & 57 & 61 \\
\hline Number of individuals & 3,154 & 1,048 & 1,056 & 1,050 \\
\hline Start-up Subsidy & 715 & 231 & 244 & 240 \\
\hline Bridging Allowance & 1,096 & 365 & 376 & 355 \\
\hline Non-participants & 1,343 & 452 & 436 & 455 \\
\hline Mean & 25.708 & 19.203 & 24.430 & 33.543 \\
\hline Standard deviation & 7.258 & 2.037 & 1.229 & 6.904 \\
\hline Median & 23.980 & 19.640 & 23.980 & 30.425 \\
\hline Minimum & 14.385 & 14.385 & 22.300 & 27.000 \\
\hline Maximum & 49.070 & 22.280 & 26.870 & 49.070 \\
\hline
\end{tabular}

Correlation between unemployment rate and GDP

Correlation coefficient

$-0.509$

Note: Labor market indicators are measured in third quarter 2003 at the level of labor agency districts. In total, 181 labor agency districts exist in West Germany.

a) In prices of 2005 . 
Table 2: Founding related characteristics

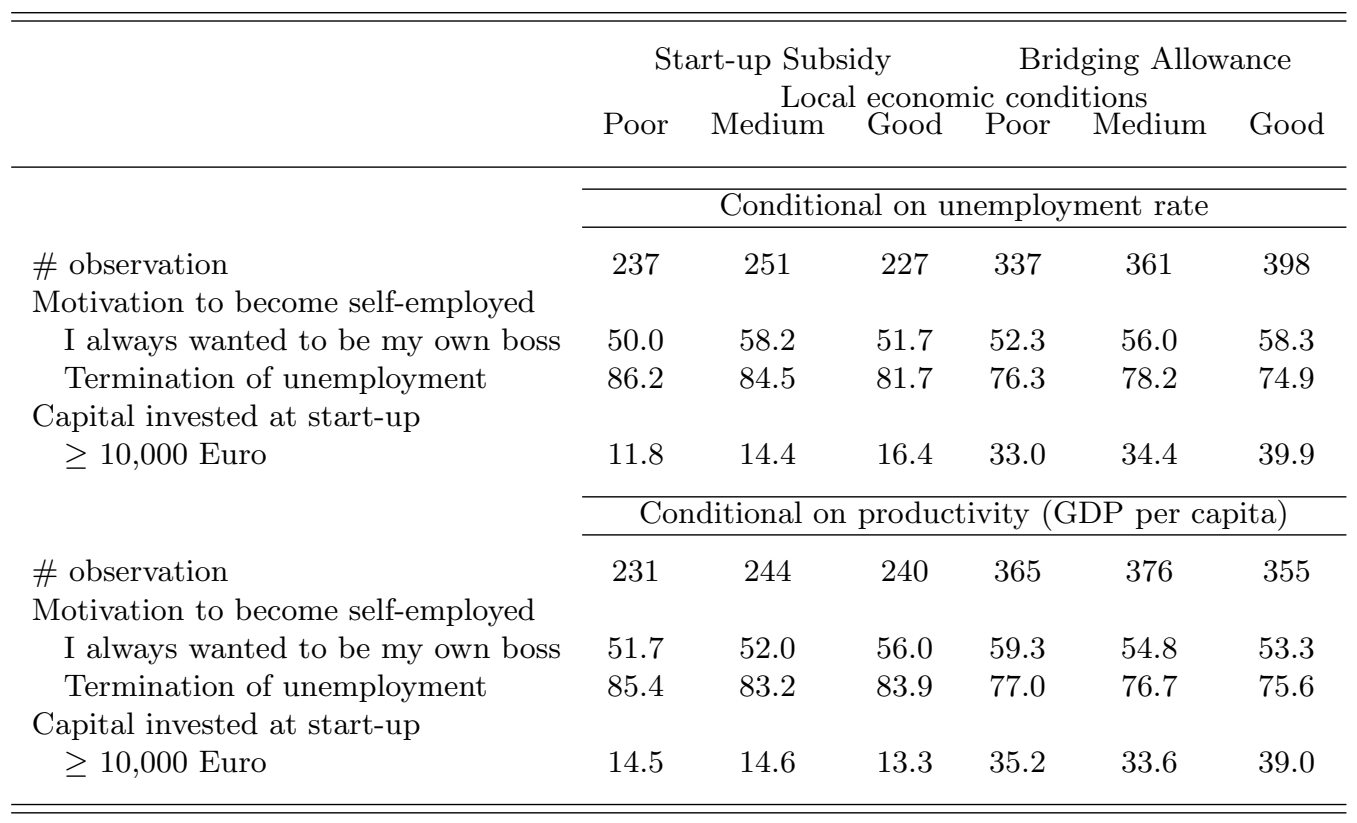

Note: All numbers are percentages unless otherwise indicated.

Table 3: Labor market status and business development 56 months after start-up

\begin{tabular}{|c|c|c|c|c|c|c|}
\hline & \multicolumn{3}{|c|}{ Start-up Subsidy } & \multicolumn{3}{|c|}{ Bridging Allowance } \\
\hline & Poor & $\begin{array}{r}\text { Loc } \\
\text { Medium }\end{array}$ & $\begin{array}{l}\text { l econor } \\
\text { Good }\end{array}$ & $\begin{array}{l}\text { ic condi } \\
\text { Poor }\end{array}$ & $\begin{array}{l}\text { ons } \\
\text { Medium }\end{array}$ & Good \\
\hline & \multicolumn{6}{|c|}{ Conditional on unemployment rate } \\
\hline \multicolumn{7}{|l|}{ Labor market status (in \%) } \\
\hline Self-employed & 62.8 & 58.2 & 61.9 & 70.5 & 67.9 & 68.1 \\
\hline Employed subject to SSC & 20.3 & 14.8 & 17.4 & 20.8 & 19.9 & 21.8 \\
\hline \multicolumn{7}{|l|}{ Income situation (net, in Euro/month) } \\
\hline Working income & 1386.3 & 1546.6 & 1452.2 & 1601.2 & 2113.6 & 2272.5 \\
\hline \multicolumn{7}{|c|}{ Employee structure conditional on being self-employed } \\
\hline Share with at least one employee (in \%) & 21.8 & 25.8 & 16.0 & 35.9 & 42.3 & 41.6 \\
\hline Number of employees ${ }^{a)}$ & 2.4 & 3.0 & 1.9 & 3.6 & 4.0 & 5.4 \\
\hline \multirow[t]{2}{*}{$\%$-change to 16 months after start-up } & 41.2 & 36.4 & -9.5 & 16.1 & 29.0 & 28.6 \\
\hline & \multicolumn{6}{|c|}{ Conditional on productivity (GDP per capita) } \\
\hline \multicolumn{7}{|l|}{ Labor market status (in \%) } \\
\hline Self-employed & 61.0 & 59.9 & 61.9 & 70.5 & 64.6 & 71.3 \\
\hline Employed subject to SSC & 19.6 & 20.4 & 22.0 & 20.7 & 20.1 & 21.7 \\
\hline \multicolumn{7}{|l|}{ Income situation (net, in Euro/month) } \\
\hline Working income & 1357.8 & 1574.1 & 1458.3 & 1674.2 & 2001.9 & 2358.4 \\
\hline Share with at least one employee (in \%) & 28.0 & 15.6 & 19.4 & 39.6 & 36.9 & 43.4 \\
\hline Number of employees ${ }^{a)}$ & 2.3 & 3.7 & 2.0 & 4.3 & 3.6 & 5.2 \\
\hline$\%$-change to 16 months after start-up & 25.2 & 35.3 & 44.1 & 45.5 & 8.7 & 24.3 \\
\hline
\end{tabular}

Note: Number of observations are reported in Table 2. SSC - Social Security Contribution.

a) Conditional on having at least one employee. 
Table 4: Causal effects of Start-up Subsidy and Bridging Allowance conditional on local economic conditions

\begin{tabular}{|c|c|c|c|c|c|c|}
\hline & \multicolumn{3}{|c|}{$\begin{array}{l}\text { Start-up Subsidy vs. } \\
\text { Non-Participation }\end{array}$} & \multicolumn{3}{|c|}{$\begin{array}{l}\text { Bridging Allowance vs. } \\
\text { Non-Participants }\end{array}$} \\
\hline & Poor & $\begin{array}{l}\text { Loce } \\
\text { Medium }\end{array}$ & $\begin{array}{l}\text { leconon } \\
\text { Good }\end{array}$ & $\begin{array}{l}\text { ic cond } \\
\text { Poor }\end{array}$ & $\begin{array}{l}\text { tions } \\
\text { Medium }\end{array}$ & Good \\
\hline & \multicolumn{6}{|c|}{ Conditional on unemployment rate } \\
\hline \# Treated & 226 & 234 & 210 & 329 & 348 & 375 \\
\hline \# Controls & 414 & 413 & 406 & 408 & 419 & 406 \\
\hline \multicolumn{7}{|c|}{ Outcome variable: "Self-employed or regular employed" } \\
\hline After 36 months (in \%-points) & 37.5 & 27.3 & 32.8 & 29.5 & 15.3 & 15.2 \\
\hline After 56 months (in \%-points) & 20.2 & 21.5 & 23.1 & 23.7 & 14.1 & 13.9 \\
\hline Total cumulated effect ( $\sum_{t=1}^{56}$, in months) & 26.4 & 22.4 & 24.1 & 20.7 & 14.7 & 14.6 \\
\hline \multicolumn{7}{|c|}{ Outcome variable: "Income 56 months after start-up" (net, in Euro/month) } \\
\hline \multirow[t]{2}{*}{ Working income } & 602 & $(248)$ & $(259)$ & 566 & 481 & 448 \\
\hline & \multicolumn{6}{|c|}{ Conditional on productivity (GDP per capita) } \\
\hline \# Treated & 220 & 233 & 220 & 347 & 369 & 319 \\
\hline \# Controls & 412 & 407 & 415 & 417 & 407 & 415 \\
\hline \multicolumn{7}{|c|}{ Outcome variable: "Self-employed or regular employed" } \\
\hline After 36 months (in \%-points) & 29.1 & 31.3 & 33.3 & 26.6 & 18.7 & 14.0 \\
\hline After 56 months (in \%-points) & 22.7 & 22.0 & 24.4 & 24.3 & 15.3 & 13.3 \\
\hline Total cumulated effect $\left(\sum_{t=1}^{56}\right.$, in months $)$ & 22.3 & 24.7 & 24.6 & 19.8 & 15.4 & 14.2 \\
\hline \multicolumn{7}{|c|}{ Outcome variable: "Income 56 months after start-up" (net, in Euro/month) } \\
\hline Working income & 590 & 374 & $(37.5)$ & 481 & 683 & 522 \\
\hline
\end{tabular}

Note: Depicted are average treatment effects on the treated as the difference in outcome variables between participants and non-participants. Effects which are not significant different from zero at the $5 \%$-level are in parentheses; standard errors are based on bootstrapping with 200 replications. 
Figure 1: Survival in self-employment conditional on local economic conditions Start-up Subsidy Bridging Allowance

Conditional on unemployment rate

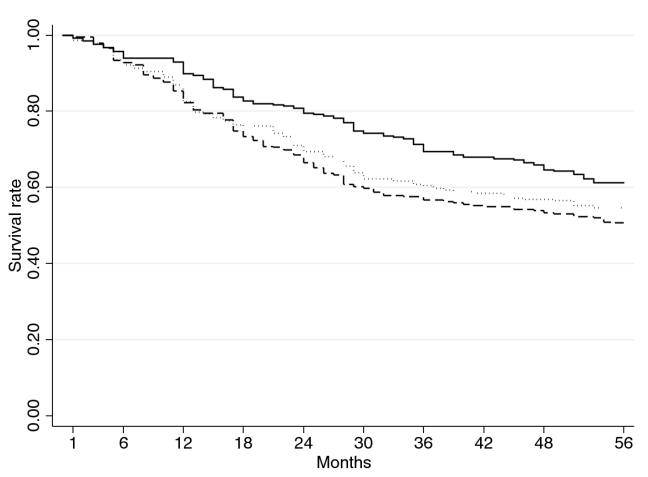

Wald $\chi^{2}(2)=6.26$, p-value $=0.044$

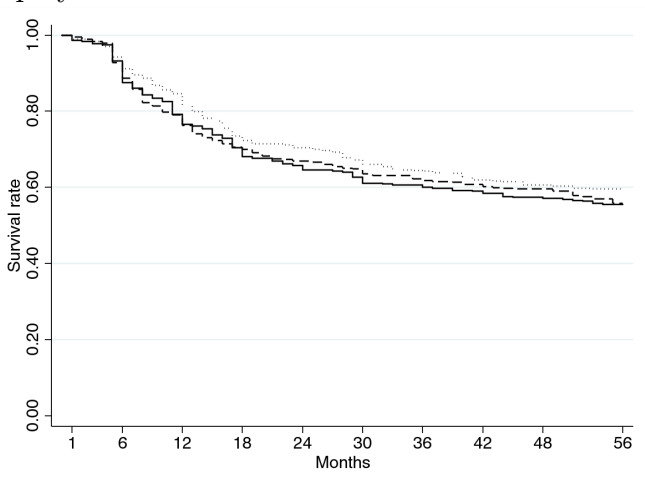

Wald $\chi^{2}(2)=1.65$, p-value $=0.438$

Conditional on productivity (GDP per capita)

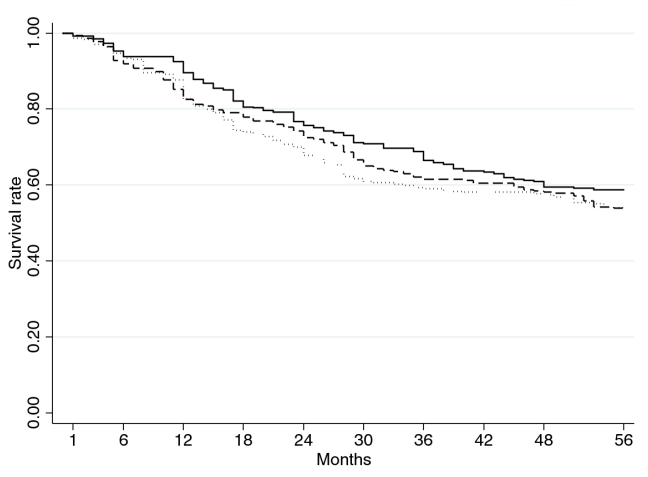

Wald $\chi^{2}(2)=1.68, \mathrm{p}$-value $=0.431$

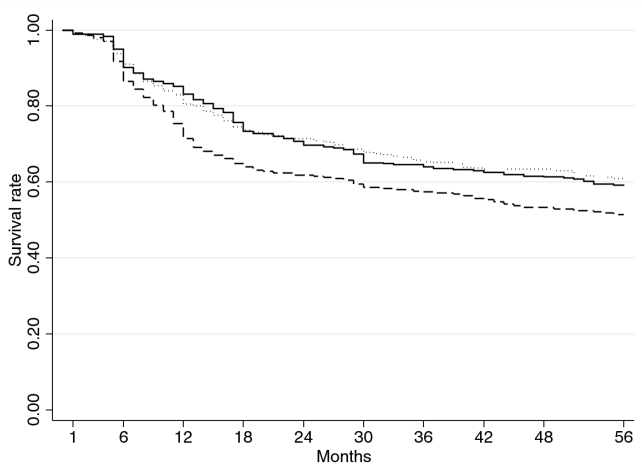

Wald $\chi^{2}(2)=7.99$, p-value $=0.018$ - Poor - - - Medium Good

Note: Depicted are Kaplan-Meier estimates for the survival probability in the first self-employment spell for program participants conditional on the prevailing economic conditions at start-up. Below the graphs, we report the test statistic and p-value based on a Cox regression-based test on the equality of the depicted survival curves whereby the underlying null hypothesis states that the survival functions are the same. 
Figure 2: Regional effect heterogeneity conditional on labor market perspectives among matched non-participants

Outcome variable: "Self-employed or regular employed"

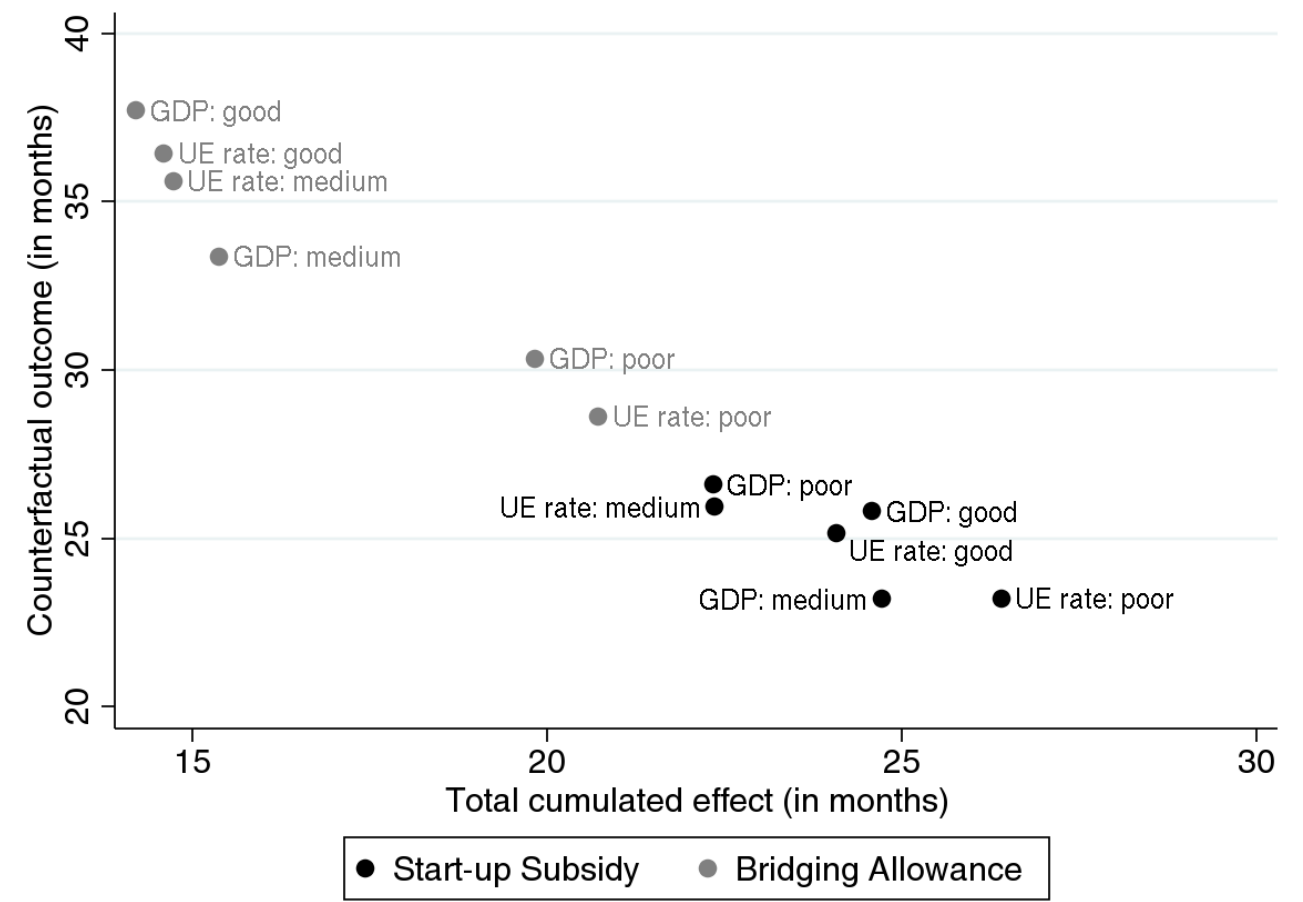

Note: Depicted on the horizontal axis are the cumulated average treatment effects on the treated consistent to Table 4 for the outcome variable "self-employment or regular employment". On the vertical axis we provide the average months spent in "self-employment or regular employment" within the observation period of 56 months for the matched non-participants. 


\section{A Supplementary Tables and Figures}

Table A.1: Propensity score estimation conditional on local unemployment rates: Start-up Subsidy vs. Non-participation

\begin{tabular}{|c|c|c|c|}
\hline & \multicolumn{3}{|c|}{$\begin{array}{l}\text { Start-up Subsidy vs. Non-participation } \\
\text { Local economic conditions }\end{array}$} \\
\hline & Poor & Medium & Good \\
\hline \multicolumn{4}{|l|}{ Age bracket (Ref.: 18 to 24 years) } \\
\hline 25 to 29 years & 0.067 & 0.218 & 0.39 \\
\hline 30 to 34 years & 0.417 & 0.092 & $0.661^{* *}$ \\
\hline 35 to 39 years & 0.133 & 0.074 & 0.165 \\
\hline 40 to 44 years & 0.29 & 0.116 & 0.315 \\
\hline 45 to 49 years & 0.447 & 0.3 & 0.32 \\
\hline 50 to 64 years & $0.781^{* *}$ & $0.801^{* *}$ & $0.836^{* * *}$ \\
\hline \multicolumn{4}{|l|}{ Marital status (Ref.: Single } \\
\hline Married & -.065 & 0.043 & -.188 \\
\hline \multicolumn{4}{|c|}{ Number of children in household (Ref.: No children) } \\
\hline one child & 0.116 & 0.198 & 0.26 \\
\hline Two or more children & 0.286 & 0.059 & 0.133 \\
\hline \multicolumn{4}{|c|}{ Health restriction that affect job placement (Ref.: No) } \\
\hline (1) & -.188 & -.210 & 0.037 \\
\hline \multicolumn{4}{|l|}{ Nationality (Ref.: German) } \\
\hline Non-German & 0.123 & 0.067 & 0.199 \\
\hline \multicolumn{4}{|l|}{ Desired working time (Ref.: Part-time) } \\
\hline Full-time & 0.608 & -.076 & 0.126 \\
\hline \multicolumn{4}{|l|}{ School leaving certificate (Ref.: No degree) } \\
\hline Lower secondary school & 0.43 & 0.323 & -.208 \\
\hline Middle secondary school & 0.44 & 0.512 & -.092 \\
\hline Specialized upper secondary school & 0.784 & 0.072 & 0.03 \\
\hline Upper secondary school & 0.468 & 0.466 & -.164 \\
\hline \multicolumn{4}{|l|}{ Occupational group (Ref.: Manufacturing) } \\
\hline Agriculture & -.085 & -.412 & 0.021 \\
\hline Technical occupations & 0.166 & $-.785^{*}$ & -.646 \\
\hline Services & 0.069 & -.350 & -.379 \\
\hline Others & -.402 & -.670 & -.425 \\
\hline \multicolumn{4}{|c|}{ Professional qualification (Ref.: Workers with tertiary education) } \\
\hline Workers with technical college education & 0.271 & 0.11 & -.051 \\
\hline Skilled workers & 0.047 & 0.188 & -.105 \\
\hline Unskilled workers & 0.2 & 0.288 & -.118 \\
\hline \multicolumn{4}{|c|}{ Duration of previous unemployment (Ref.: $<1$ month) } \\
\hline$\geq 1$ month -3 months & $-1.390^{* * *}$ & $-1.560^{* * *}$ & $-1.737^{* * *}$ \\
\hline$\geq 3$ months $-<6$ months & $-1.632^{* * *}$ & $-1.529^{* * *}$ & $-1.473^{* * *}$ \\
\hline$\geq 6$ months $-<1$ year & $-1.426^{* * *}$ & $-1.700^{* * *}$ & $-1.648^{* * *}$ \\
\hline$\geq 1$ year $-<2$ years & $-1.446^{* * *}$ & $-2.005^{* * *}$ & $-1.659^{* * *}$ \\
\hline$\geq 2$ years & $-1.324^{* * *}$ & $-1.086^{* * *}$ & $-1.800^{* * *}$ \\
\hline \multicolumn{4}{|c|}{ Professional experience (Ref.: without professional experience) } \\
\hline with professional experience & 0.024 & -.128 & -.164 \\
\hline \multicolumn{4}{|l|}{ Last employment } \\
\hline Duration of last employment & 0.002 & 0.0006 & $0.003^{*}$ \\
\hline \multicolumn{4}{|l|}{ Placement propositions } \\
\hline Number of placement propositions & $-.024^{* *}$ & 0.005 & $-.015^{* *}$ \\
\hline
\end{tabular}


Start-up Subsidy vs. Non-participation Local economic conditions

Poor Medium Good

\begin{tabular}{|c|c|c|c|}
\hline \multicolumn{4}{|l|}{ Employment status before job-seeking (Ref.: Employment) } \\
\hline Self-employed & $0.886^{* * *}$ & 0.089 & $0.566^{* *}$ \\
\hline School attendance/never employed before/apprenticeship & $0.326^{*}$ & 0.293 & 0.378 \\
\hline Unemployable & 0.272 & -.015 & 0.36 \\
\hline $\begin{array}{l}\text { Others, but at least once employed before } \\
\text { Others }\end{array}$ & $0.73^{* * *}$ & $0.474^{* *}$ & $0.352^{*}$ \\
\hline \multicolumn{4}{|l|}{ Regional cluster (Ref.: II a) } \\
\hline \multicolumn{4}{|l|}{ II $b$} \\
\hline III a & 0.012 & 0.015 & \\
\hline III $b$ & & -.416 & \\
\hline III c & & -.199 & $-.722^{*}$ \\
\hline IV & & 0.247 & -.416 \\
\hline $\mathrm{V}$ a & & & -.574 \\
\hline $\mathrm{V} b$ & & & -.654 \\
\hline $\mathrm{V} \mathrm{c}$ & & & -.712 \\
\hline Remaining unemployment benefit entitlement (in months) & -.014 & $-.032^{* *}$ & $-.035^{* * *}$ \\
\hline Unemployment benefit level (in Euro) & $-.039^{* * *}$ & $-.025^{* * *}$ & $-.032^{* * *}$ \\
\hline $\begin{array}{l}\text { Average daily income from regular } \\
\text { employment in first half of } 2003\end{array}$ & -.002 & -.002 & -.004 \\
\hline \multicolumn{4}{|l|}{ Intergenerational transmission } \\
\hline Parents are/were self-employed & $0.367^{* *}$ & $0.784^{* * *}$ & 0.175 \\
\hline \multicolumn{4}{|l|}{ Regional macroeconomic conditions } \\
\hline Unemployment rate & $0.096^{* *}$ & -.106 & $-.160^{*}$ \\
\hline${\text { Vacancy } \text { rate }^{a)}}$ & $0.12^{* *}$ & $-.079^{* * *}$ & -.001 \\
\hline GDP per capita & $0.072^{*}$ & 0.006 & 0.003 \\
\hline Constant & $-3.338^{* *}$ & $3.183^{* *}$ & $3.897^{* * *}$ \\
\hline Number of observations & 646 & 656 & 627 \\
\hline Pseudo $\mathrm{R}^{2}$ & 0.166 & 0.224 & 0.224 \\
\hline Log-likelihood & -351.911 & -335.623 & -315.679 \\
\hline
\end{tabular}

Note: $* 10 \%, * * 5 \%, * * * 1 \%$ significance level. Differences in numbers of observations compared to Table 1 are due to missing values for some variables.

a) Available vacancies as the share of the stock in unemployment. 
Table A.2: Propensity score estimation conditional on local GDP per capita: Startup Subsidy vs. Non-participation

\begin{tabular}{|c|c|c|c|}
\hline & \multicolumn{3}{|c|}{$\begin{array}{l}\text { Start-up Subsidy vs. Non-participation } \\
\text { Local economic conditions }\end{array}$} \\
\hline & Poor & Medium & Good \\
\hline \multicolumn{4}{|l|}{ Age bracket (Ref.: 18 to 24 years) } \\
\hline 25 to 29 years & 0.001 & 0.425 & $0.558^{*}$ \\
\hline 30 to 34 years & 0.361 & 0.453 & $0.639^{* *}$ \\
\hline 35 to 39 years & -.087 & 0.344 & 0.284 \\
\hline 40 to 44 years & 0.358 & 0.449 & 0.199 \\
\hline 45 to 49 years & 0.497 & 0.459 & 0.512 \\
\hline 50 to 64 years & $0.952^{* * *}$ & $0.8255^{* *}$ & $0.913^{* * *}$ \\
\hline \multicolumn{4}{|l|}{ Marital status (Ref.: Single) } \\
\hline Married & -.115 & -.132 & -.057 \\
\hline \multicolumn{4}{|c|}{ Number of children in household (Ref.: No children) } \\
\hline One child & 0.101 & $0.337^{*}$ & 0.049 \\
\hline Two or more children & $0.381^{* *}$ & -.054 & 0.223 \\
\hline \multicolumn{4}{|c|}{ Health restriction that affect job placement (Ref.: No) } \\
\hline Yes & -.124 & -.054 & -.167 \\
\hline \multicolumn{4}{|l|}{ Nationality (Ref.: German) } \\
\hline Non-German & 0.178 & $0.366^{* * *}$ & -.134 \\
\hline \multicolumn{4}{|l|}{ Desired working time (Ref.: Part-time) } \\
\hline Full-time & $1.409^{* *}$ & -.405 & -.143 \\
\hline \multicolumn{4}{|l|}{ School leaving certificate (Ref.: No degree) } \\
\hline Lower secondary school & -.258 & 0.301 & 0.017 \\
\hline Middle secondary school & -.146 & 0.258 & 0.315 \\
\hline Specialized upper secondary school & -.038 & 0.1 & 0.324 \\
\hline Upper secondary school & -.047 & 0.07 & 0.336 \\
\hline \multicolumn{4}{|l|}{ Occupational group (Ref.: Manufacturing) } \\
\hline Agriculture & -.048 & -.174 & -.293 \\
\hline Technical occupations & 0.114 & -.219 & $-.834^{*}$ \\
\hline Services & 0.015 & -.046 & -.566 \\
\hline Others & -.459 & -.440 & -.706 \\
\hline \multicolumn{4}{|c|}{ Professional qualification (Ref.: Workers with tertiary education) } \\
\hline Workers with technical college education & 0.321 & 0.188 & -.111 \\
\hline Skilled workers & 0.371 & -.252 & 0.065 \\
\hline Unskilled workers & $0.444^{*}$ & -.002 & 0.043 \\
\hline \multicolumn{4}{|c|}{ Duration of previous unemployment (Ref.: $<1$ month) } \\
\hline$\geq 1$ month -3 months & $-1.342^{* * *}$ & $-1.656^{* * *}$ & $-1.748^{* * *}$ \\
\hline$\geq 3$ months $-<6$ months & $-1.524^{* * *}$ & $-1.443^{* * *}$ & $-1.768^{* * *}$ \\
\hline$\geq 6$ months $-<1$ year & $-1.212^{* * *}$ & $-1.423^{* * *}$ & $-2.030^{* * *}$ \\
\hline$\geq 1$ year $-<2$ years & $-1.443^{* * *}$ & $-1.573^{* * *}$ & $-2.019^{* * *}$ \\
\hline$\geq 2$ years & $-.825^{* *}$ & $-1.426^{* * *}$ & $-1.714^{* * *}$ \\
\hline \multicolumn{4}{|c|}{ Professional experience (Ref.: without professional experience) } \\
\hline with professional experience & 0.173 & $-.291^{*}$ & -.140 \\
\hline \multicolumn{4}{|l|}{ Last employment } \\
\hline Duration of last employment & 0.0005 & 0.002 & 0.002 \\
\hline \multicolumn{4}{|l|}{ Placement propositions } \\
\hline Number of placement propositions & $-.041^{* * *}$ & -.007 & -.0007 \\
\hline
\end{tabular}


Start-up Subsidy vs. Non-participation Local economic conditions

Poor Medium Good

\begin{tabular}{|c|c|c|c|}
\hline \multicolumn{4}{|l|}{ Employment status before job-seeking (Ref.: Employment) } \\
\hline Self-employed & $0.899^{* * *}$ & $0.593^{* *}$ & 0.096 \\
\hline School attendance/never employed before/apprenticeship & $0.642^{* * *}$ & 0.328 & 0.213 \\
\hline Unemployable & 0.038 & $0.413^{*}$ & $0.449^{*}$ \\
\hline $\begin{array}{l}\text { Others, but at least once employed before } \\
\text { Others }\end{array}$ & $0.756^{* * *}$ & $0.568^{* * *}$ & $0.398^{* *}$ \\
\hline \multicolumn{4}{|l|}{ Regional cluster (Ref.: II a) } \\
\hline II b & -.219 & 0.164 & 0.053 \\
\hline III a & 0.418 & -.061 & 0.662 \\
\hline III b & 0.174 & 0.255 & -.627 \\
\hline III c & -.347 & -.178 & -.439 \\
\hline IV & & & -.002 \\
\hline $\mathrm{V}$ a & & -.236 & -.201 \\
\hline $\mathrm{V} b$ & -.333 & -.234 & -.295 \\
\hline $\mathrm{V} \mathrm{c}$ & & -.304 & -.159 \\
\hline Remaining unemployment benifit entitlement (in months) & -.009 & -.019 & $-.048^{* * *}$ \\
\hline Unemployment benefit level (in Euro) & $-.042^{* * *}$ & $-.029^{* * *}$ & $-.028^{* * *}$ \\
\hline $\begin{array}{l}\text { Average daily income from regular } \\
\text { employment in first half of } 2003\end{array}$ & 0.002 & -.005 & -.003 \\
\hline \multicolumn{4}{|l|}{ Intergenerational transmission } \\
\hline Parents are/were self-employed & $0.559^{* * *}$ & $0.353^{* *}$ & $0.39^{* * *}$ \\
\hline \multicolumn{4}{|l|}{ Regional macroeconomic conditions } \\
\hline Unemployment Rate & 0.039 & 0.005 & -.105 \\
\hline Vacancy rate ra $^{a}$ & $0.099^{* * *}$ & 0.005 & -.024 \\
\hline GDP per capita & 0.041 & $0.165^{* * *}$ & 0.004 \\
\hline Constant & -2.149 & -2.130 & $3.474^{* *}$ \\
\hline Number of observations & 636 & 646 & 648 \\
\hline Pseudo $\mathrm{R}^{2}$ & 0.209 & 0.205 & 0.218 \\
\hline Log-likelihood & -326.257 & -338.403 & -331.188 \\
\hline
\end{tabular}

Note: $* 10 \%, * * 5 \%, * * * 1 \%$ significance level. Differences in numbers of observations compared to Table 1 are due to missing values for some variables.

a) Available vacancies as the share of the stock in unemployment. 
Table A.3: Propensity score estimation conditional on local unemployment rates: Bridging Allowance vs. Non-participation

\begin{tabular}{|c|c|c|c|}
\hline \multirow{3}{*}{ Age bracket (Ref.: 18 to 24 years) } & \multicolumn{3}{|c|}{$\begin{array}{l}\text { Bridging Allowance vs. Non-participation } \\
\text { Local economic conditions }\end{array}$} \\
\hline & \multicolumn{3}{|c|}{ Poor $\begin{array}{c}\text { Local economic conditions } \\
\text { Medium }\end{array}$} \\
\hline & & & \\
\hline 25 to 29 years & -.142 & $0.704^{* *}$ & 0.151 \\
\hline 30 to 34 years & 0.343 & $0.571^{*}$ & 0.113 \\
\hline 35 to 39 years & 0.246 & 0.531 & 0.232 \\
\hline 40 to 44 years & 0.206 & 0.267 & 0.131 \\
\hline 45 to 49 years & 0.035 & 0.37 & 0.16 \\
\hline 50 to 64 years & -.108 & 0.486 & 0.317 \\
\hline \multicolumn{4}{|l|}{ Marital status (Ref.: Single) } \\
\hline Married & $-.231^{*}$ & 0.06 & -.056 \\
\hline \multicolumn{4}{|c|}{ Number of children in household (Ref.: No children) } \\
\hline One child & -.107 & -.054 & -.125 \\
\hline Two or more children & -.049 & -.234 & -.130 \\
\hline \multicolumn{4}{|c|}{ Health restriction that affect job placement (Ref.: No) } \\
\hline Yes & 0.213 & -.221 & -.141 \\
\hline \multicolumn{4}{|l|}{ Nationality (Ref.: German) } \\
\hline Non-German & 0.103 & 0.121 & $0.24^{* *}$ \\
\hline \multicolumn{4}{|l|}{ Desired working time (Ref.: Part-time) } \\
\hline Full-time & & 0.982 & -.434 \\
\hline \multicolumn{4}{|l|}{ School leaving certificate (Ref.: No degree) } \\
\hline Lower secondary school & 0.394 & 0.296 & 0.097 \\
\hline Middle secondary school & 0.512 & 0.355 & 0.122 \\
\hline Specialized upper secondary school & 0.688 & 0.329 & 0.212 \\
\hline Upper secondary school & 0.68 & 0.19 & 0.233 \\
\hline \multicolumn{4}{|l|}{ Occupational group (Ref.: Manufacturing) } \\
\hline Agriculture & 0.274 & 0.242 & 0.063 \\
\hline Technical occupations & 0.449 & 0.59 & 0.052 \\
\hline Services & 0.31 & 0.432 & -.130 \\
\hline Others & -.091 & -.004 & -.518 \\
\hline \multicolumn{4}{|c|}{ Professional qualification (Ref.: Workers with tertiary education) } \\
\hline Workers with technical college education & 0.114 & -.298 & 0.11 \\
\hline Skilled workers & 0.147 & -.104 & 0.136 \\
\hline Unskilled workers & 0.275 & -.148 & 0.154 \\
\hline \multicolumn{4}{|c|}{ Duration of previous unemployment (Ref.: $<1$ month) } \\
\hline$\geq 1$ month -3 months & $-.985^{* * *}$ & $-.980^{* * *}$ & $-1.052^{* * *}$ \\
\hline$\geq 3$ months $-<6$ months & $-1.002^{* * *}$ & $-1.172^{* * *}$ & $-.985^{* * *}$ \\
\hline$\geq 6$ months $-<1$ year & $-.795^{* * *}$ & $-1.309^{* * *}$ & $-1.134^{* * *}$ \\
\hline$\geq 1$ year $-<2$ years & $-.958^{* * *}$ & $-1.251^{* * *}$ & $-1.182^{* * *}$ \\
\hline$\geq 2$ years & $-1.104^{* * *}$ & $-.937^{*}$ & $-1.576^{* * *}$ \\
\hline \multicolumn{4}{|c|}{ Professional experience (Ref.: without professional experience) } \\
\hline with professional experience & -.141 & -.214 & $-.348^{* *}$ \\
\hline \multicolumn{4}{|l|}{ Last employment } \\
\hline Duration of last employment & $0.003^{* *}$ & 0.001 & $0.003^{* *}$ \\
\hline \multicolumn{4}{|l|}{ Placement propositions } \\
\hline Number of placement propositions & -.006 & -.011 & $-.014^{* *}$ \\
\hline
\end{tabular}


Bridging Allowance vs. Non-participation Local economic conditions

Poor Medium Good

\begin{tabular}{|c|c|c|c|}
\hline \multicolumn{4}{|l|}{ Employment status before job-seeking (Ref.: Employment) } \\
\hline Self-employed & -.463 & -.406 & -.263 \\
\hline School attendance/never employed before/apprenticeship & $0.304^{*}$ & 0.051 & 0.371 \\
\hline Unemployable & 0.083 & -.099 & -.027 \\
\hline $\begin{array}{l}\text { Others, but at least once employed before } \\
\text { Others }\end{array}$ & 0.242 & $0.615^{* * *}$ & 0.025 \\
\hline \multicolumn{4}{|l|}{ Regional cluster (Ref.: II a) } \\
\hline III a & $-1.440^{*}$ & -.197 & \\
\hline III $b$ & & -.223 & \\
\hline III c & & $-.393^{*}$ & -.003 \\
\hline IV & & -.237 & -.076 \\
\hline $\mathrm{V}$ a & & -.039 & 0.049 \\
\hline $\mathrm{V} b$ & & & -.394 \\
\hline $\mathrm{V} \mathrm{c}$ & & & -.236 \\
\hline Remaining unemployment benefit entitlement (in months) & -.012 & -.004 & $-.044^{* * *}$ \\
\hline Unemployment benefit level (in Euro) & $0.025^{* * *}$ & $0.022^{* * *}$ & $0.026^{* * *}$ \\
\hline $\begin{array}{l}\text { Average daily income from regular } \\
\text { employment in first half of } 2003\end{array}$ & -.001 & $-.004^{* *}$ & -.0007 \\
\hline \multicolumn{4}{|l|}{ Intergenerational transmission } \\
\hline Parents are/were self-employed & $0.515^{* * *}$ & $0.704^{* * *}$ & $0.254^{* *}$ \\
\hline \multicolumn{4}{|l|}{ Regional macroeconomic conditions } \\
\hline Unemployment Rate & $-.069^{*}$ & -.108 & $-.152^{* *}$ \\
\hline Vacancy rate $^{a)}$ & -.035 & $-.041^{*}$ & 0.0002 \\
\hline GDP per capita & 0.018 & -.0003 & 0.003 \\
\hline Constant & 0.585 & -.079 & 1.729 \\
\hline Number of observations & 743 & 771 & 791 \\
\hline Pseudo $\mathrm{R}^{2}$ & 0.108 & 0.136 & 0.124 \\
\hline Log-likelihood & -456.142 & -459.37 & -480.303 \\
\hline
\end{tabular}

Note: $* 10 \%, * * 5 \%, * * * 1 \%$ significance level. Differences in numbers of observations compared to Table 1 are due to missing values for some variables.

a) Available vacancies as the share of the stock in unemployment. 
Table A.4: Propensity score estimation conditional on local GDP per capita: Bridging Allowance vs. Non-participation

\begin{tabular}{|c|c|c|c|}
\hline & \multicolumn{3}{|c|}{$\begin{array}{l}\text { Bridging Allowance vs. Non-participation } \\
\text { Local economic conditions }\end{array}$} \\
\hline & Poor & Medium & Good \\
\hline \multicolumn{4}{|l|}{ Age bracket (Ref.: 18 to 24 years) } \\
\hline 25 to 29 years & 0.014 & 0.01 & 0.559 \\
\hline 30 to 34 years & 0.436 & 0.029 & 0.399 \\
\hline 35 to 39 years & 0.039 & 0.263 & 0.397 \\
\hline 40 to 44 years & 0.283 & 0.038 & 0.108 \\
\hline 45 to 49 years & -.064 & 0.074 & 0.319 \\
\hline 50 to 64 years & -.149 & 0.236 & 0.213 \\
\hline \multicolumn{4}{|l|}{ Marital status (Ref.: Single) } \\
\hline Married & -.085 & -.184 & 0.056 \\
\hline \multicolumn{4}{|c|}{ Number of children in household (Ref.: No children) } \\
\hline One child & -.044 & 0.024 & $-.299^{*}$ \\
\hline Two or more children & -.120 & -.085 & $-.298^{*}$ \\
\hline \multicolumn{4}{|c|}{ Health restriction that affect job placement (Ref.: No) } \\
\hline Zes & -.159 & 0.205 & -.127 \\
\hline \multicolumn{4}{|l|}{ Nationality (Ref.: German) } \\
\hline Non-German & 0.032 & $0.255^{* *}$ & 0.097 \\
\hline \multicolumn{4}{|l|}{ Desired working time (Ref.: Part-time) } \\
\hline Full-time & $1.241^{* *}$ & 0.272 & -.248 \\
\hline \multicolumn{4}{|l|}{ School leaving certificate (Ref.: No degree) } \\
\hline Lower secondary school & -.208 & 0.943 & 0.347 \\
\hline Middle secondary school & -.297 & $1.151^{*}$ & 0.344 \\
\hline Specialized upper secondary school & 0.027 & 1.002 & 0.53 \\
\hline Upper secondary school & -.200 & $1.163^{*}$ & 0.273 \\
\hline \multicolumn{4}{|l|}{ Occupational group (Ref.: Manufacturing) } \\
\hline Agriculture & 0.027 & 0.33 & -.115 \\
\hline Technical occupations & 0.07 & 0.472 & 0.147 \\
\hline Services & -.028 & 0.412 & -.144 \\
\hline Others & -.446 & -.178 & -.327 \\
\hline \multicolumn{4}{|c|}{ Professional qualification (Ref.: Workers with tertiary education) } \\
\hline Workers with technical college education & -.237 & 0.05 & 0.05 \\
\hline Skilled workers & -.025 & 0.028 & 0.122 \\
\hline Unskilled workers & -.032 & 0.21 & 0.067 \\
\hline \multicolumn{4}{|c|}{ Duration of previous unemployment (Ref.: $<1$ month) } \\
\hline$\geq 1$ month -3 months & $-.856^{* * *}$ & $-.927^{* * *}$ & $-1.080^{* * *}$ \\
\hline$\geq 3$ months $-<6$ months & $-.962^{* * *}$ & $-.871^{* * *}$ & $-1.359^{* * *}$ \\
\hline$\geq 6$ months $-<1$ year & $-.683^{* *}$ & $-.838^{* *}$ & $-1.549^{* * *}$ \\
\hline$\geq 1$ year $-<2$ years & $-.794^{* * *}$ & $-1.062^{* * *}$ & $-1.422^{* * *}$ \\
\hline$\geq 2$ years & $-.713^{*}$ & $-1.505^{* * *}$ & $-1.187^{* *}$ \\
\hline \multicolumn{4}{|c|}{ Professional experience (Ref.: without professional experience) } \\
\hline with professional experience & -.101 & $-.331^{* *}$ & -.231 \\
\hline \multicolumn{4}{|l|}{ Last employment } \\
\hline Duration of last employment & $0.004^{* * *}$ & $0.002^{*}$ & $0.002^{*}$ \\
\hline \multicolumn{4}{|l|}{ Placement propositions } \\
\hline Number of placement propositions & -.010 & -.007 & $-.019^{* *}$ \\
\hline
\end{tabular}


Bridging Allowance vs. Non-participation Local economic conditions

Poor Medium Good

\begin{tabular}{|c|c|c|c|}
\hline \multicolumn{4}{|l|}{ Employment status before job-seeking (Ref.: Employment) } \\
\hline Self-employed & -.709 & $-.612^{*}$ & -.079 \\
\hline School attendance/never employed before/apprenticeship & $0.372^{* *}$ & 0.072 & 0.166 \\
\hline Unemployable & -.180 & 0.115 & 0.24 \\
\hline $\begin{array}{l}\text { Others, but at least once employed before } \\
\text { Others }\end{array}$ & $0.491^{* *}$ & 0.292 & 0.002 \\
\hline \multicolumn{4}{|l|}{ Regional cluster (Ref.: II a) } \\
\hline II b & -.907 & -0.054 & -.223 \\
\hline III a & $-1.582^{* * *}$ & -.298 & -.401 \\
\hline III b & $-1.466^{* *}$ & -.212 & $-.964^{*}$ \\
\hline III c & $-1.568^{* *}$ & -.517 & -.528 \\
\hline IV & & & -.602 \\
\hline $\mathrm{V}$ a & & 0.145 & -.372 \\
\hline $\mathrm{V} b$ & $-1.578^{* *}$ & -.533 & $-.966^{*}$ \\
\hline $\mathrm{V} \mathrm{c}$ & & -.274 & -.675 \\
\hline Remaining unemployment benefit entitlement (in months) & -.017 & $-.018^{*}$ & $-.020^{*}$ \\
\hline Unemployment benefit level (in Euro) & $0.021^{* * *}$ & $0.023^{* * *}$ & $0.031^{* * *}$ \\
\hline $\begin{array}{l}\text { Average daily income from regular } \\
\text { employment in first half of } 2003\end{array}$ & 0.001 & -.001 & $-.005^{* * *}$ \\
\hline \multicolumn{4}{|l|}{ Intergenerational transmission } \\
\hline Parents are/were self-employed & $0.581^{* * *}$ & $0.493^{* * *}$ & $0.354^{* * *}$ \\
\hline \multicolumn{4}{|l|}{ Regional macroeconomic conditions } \\
\hline Unemployment Rate & $-.073^{*}$ & -.047 & $-.109^{*}$ \\
\hline Vacancy rate $\mathrm{ra}^{a}$ & 0.02 & 0.002 & 0.004 \\
\hline GDP per capita & 0.03 & -.005 & $0.023^{* *}$ \\
\hline Constant & 0.233 & -.642 & 0.713 \\
\hline Number of observations & 775 & 777 & 759 \\
\hline Pseudo $\mathrm{R}^{2}$ & 0.127 & 0.117 & 0.157 \\
\hline Log-likelihood & -466.97 & -474.72 & -440.738 \\
\hline
\end{tabular}

Note: $* 10 \%,{ }^{*} 5 \%, * * * 1 \%$ significance level. Differences in numbers of observations compared to Table 1 are due to missing values for some variables.

a) Available vacancies as the share of the stock in unemployment. 
Table A.5: Matching quality across regional subgroups: Conditional on local unemployment rate

\begin{tabular}{|c|c|c|c|c|}
\hline & \multicolumn{2}{|c|}{ Start-up Subsidy } & \multicolumn{2}{|c|}{ Bridging Allowance } \\
\hline & Before matching & After matching & Before matching & After matching \\
\hline \multicolumn{5}{|c|}{ Poor economic conditions } \\
\hline \multicolumn{5}{|l|}{ t-test of equal means ${ }^{a}$ ) } \\
\hline $1 \%$-level & 8 & 0 & 6 & 0 \\
\hline $5 \%$-level & 12 & 2 & 11 & 1 \\
\hline $10 \%$-level & 14 & 2 & 14 & 1 \\
\hline Mean standardized bias & 10.192 & 5.015 & 9.564 & 2.957 \\
\hline \multicolumn{5}{|c|}{ Number of variables with standardized bias of a certain amount } \\
\hline$<1 \%$ & 5 & 6 & 5 & 12 \\
\hline $1 \%$ until $<3 \%$ & 8 & 17 & 5 & 18 \\
\hline $3 \%$ until $<5 \%$ & 8 & 12 & 5 & 14 \\
\hline $5 \%$ until $<10 \%$ & 16 & 15 & 17 & 9 \\
\hline$\geq 10 \%$ & 17 & 4 & 21 & 0 \\
\hline Pseudo- $R^{2}$ & 0.165 & 0.024 & 0.108 & 0.010 \\
\hline \multicolumn{5}{|c|}{ Medium economic conditions } \\
\hline \multicolumn{5}{|l|}{ t-test of equal means ${ }^{a}$ ) } \\
\hline $1 \%$-level & 13 & 0 & 4 & 0 \\
\hline $5 \%$-level & 20 & 2 & 12 & 1 \\
\hline $10 \%$-level & 25 & 5 & 18 & 1 \\
\hline Mean standardized bias & 15.735 & 7.232 & 10.045 & 2.810 \\
\hline \multicolumn{5}{|c|}{ Number of variables with standardized bias of a certain amount } \\
\hline$<1 \%$ & 2 & 4 & 4 & 13 \\
\hline $1 \%$ until $<3 \%$ & 2 & 9 & 6 & 21 \\
\hline $3 \%$ until $<5 \%$ & 4 & 10 & 6 & 11 \\
\hline $5 \%$ until $<10 \%$ & 16 & 18 & 14 & 10 \\
\hline$\geq 10 \%$ & 30 & 13 & 25 & 0 \\
\hline Pseudo- $R^{2}$ & 0.223 & 0.042 & 0.136 & 0.012 \\
\hline \multicolumn{5}{|c|}{ Good economic conditions } \\
\hline \multicolumn{5}{|l|}{ t-test of equal means ${ }^{a}$ ) } \\
\hline $1 \%$-level & 12 & 0 & 5 & 0 \\
\hline $5 \%$-level & 18 & 2 & 11 & 1 \\
\hline $10 \%$-level & 24 & 3 & 16 & 1 \\
\hline Mean standardized bias & 15.196 & 5.145 & 9.368 & 3.824 \\
\hline \multicolumn{5}{|c|}{ Number of variables with standardized bias of a certain amount } \\
\hline$<1 \%$ & 4 & 9 & 1 & 9 \\
\hline $1 \%$ until $<3 \%$ & 2 & 14 & 12 & 15 \\
\hline $3 \%$ until $<5 \%$ & 3 & 8 & 4 & 13 \\
\hline $5 \%$ until $<10 \%$ & 11 & 19 & 18 & 16 \\
\hline$\geq 10 \%$ & 35 & 5 & 20 & 2 \\
\hline Pseudo-R ${ }^{2}$ & 0.223 & 0.024 & 0.124 & 0.016 \\
\hline
\end{tabular}

a) Depicted is the number of variables which differ significantly between treated and controls. The decision is based on a simple $t$-test of equal means. There are 53 to 55 observable variables (depending on PS specification) in total. 
Table A.6: Matching quality across regional subgroups: Conditional on local GDP per capita

\begin{tabular}{|c|c|c|c|c|}
\hline & \multicolumn{2}{|c|}{ Start-up Subsidy } & \multicolumn{2}{|c|}{ Bridging Allowance } \\
\hline & Before matching & After matching & Before matching & After matching \\
\hline \multicolumn{5}{|c|}{ Poor economic conditions } \\
\hline \multicolumn{5}{|l|}{ t-test of equal means ${ }^{a)}$} \\
\hline $1 \%$-level & 8 & 0 & 5 & 0 \\
\hline $5 \%$-level & 13 & 1 & 11 & 1 \\
\hline $10 \%$-level & 17 & 1 & 16 & 1 \\
\hline Mean standardized bias & 11.429 & 3.750 & 9.432 & 2.785 \\
\hline \multicolumn{5}{|c|}{ Number of variables with standardized bias of a certain amount } \\
\hline$<1 \%$ & 2 & 13 & 4 & 15 \\
\hline $1 \%$ until $<3 \%$ & 8 & 19 & 6 & 23 \\
\hline $3 \%$ until $<5 \%$ & 8 & 10 & 9 & 10 \\
\hline $5 \%$ until $<10 \%$ & 13 & 10 & 18 & 10 \\
\hline$\geq 10 \%$ & 26 & 5 & 21 & 0 \\
\hline
\end{tabular}

Pseudo-R ${ }^{2}$

0.209

0.022

0.127

0.013

t-test of equal means ${ }^{a)}$

Medium economic conditions

$5 \%$-level

$10 \%$-level

12

14

20

13.975

Mean standardized bias

$$
\begin{aligned}
& <1 \% \\
& 1 \% \text { until }<3 \% \\
& 3 \% \text { until }<5 \% \\
& 5 \% \text { until }<10 \% \\
& \geq 10 \%
\end{aligned}
$$

Pseudo-R ${ }^{2}$

t-test of equal means ${ }^{a)}$

$1 \%$-level

$5 \%$-level

$10 \%$-level

Mean standardized bias

Number of variables with
$<1 \%$

$1 \%$ until $<3 \%$

$3 \%$ until $<5 \%$

$5 \%$ until $<10 \%$

$\geq 10 \%$

Pseudo-R ${ }^{2}$

bias of a certain amount

$\begin{array}{rr}2 & 5 \\ 7 & 18 \\ 6 & 18 \\ 12 & 12 \\ 30 & 4 \\ 0.206 & 0.018\end{array}$

$\begin{array}{ll}0.206 & 0.018\end{array}$

Good economic conditions

a) Depicted is the number of variables which differ significantly between treated and controls. The decision is based on a simple $t$-test of equal means. There are 56 to 59 observable variables (depending on PS specification) in total. 
Table A.7: Balancing of pre-treatment outcome variables across regional subgroups

\begin{tabular}{|c|c|c|c|c|c|c|}
\hline & \multicolumn{3}{|c|}{ Before matching } & \multicolumn{3}{|c|}{ After matching } \\
\hline & Treated & Controls & p-value & Treated & Controls & p-value \\
\hline \multicolumn{7}{|c|}{ Start-up Subsidy } \\
\hline \multicolumn{7}{|l|}{ Conditional on unemployment rates } \\
\hline \multicolumn{7}{|c|}{ Poor economic conditions } \\
\hline Months in employment in 2002 & 5.112 & 6.413 & 0.001 & 5.177 & 4.634 & 0.235 \\
\hline Income from employment in 2002 (in $€ /$ day) & 22.640 & 34.056 & 0.000 & 22.892 & 21.365 & 0.529 \\
\hline \multicolumn{7}{|c|}{ Medium economic conditions } \\
\hline Months in employment in 2002 & 5.444 & 7.354 & 0.000 & 5.359 & 5.571 & 0.639 \\
\hline Income from employment in 2002 (in $€ /$ day) & 27.933 & 51.774 & 0.000 & 28.155 & 31.917 & 0.198 \\
\hline \multicolumn{7}{|c|}{ Good economic conditions } \\
\hline Months in employment in 2002 & 5.688 & 7.347 & 0.000 & 5.681 & 5.395 & 0.545 \\
\hline Income from employment in 2002 (in $€ /$ day) & 29.016 & 54.293 & 0.000 & 29.341 & 31.164 & 0.569 \\
\hline \multicolumn{7}{|l|}{ Conditional on productivity (GDP per capita) } \\
\hline \multicolumn{7}{|c|}{ Poor economic conditions } \\
\hline Months in employment in 2002 & 5.513 & 6.704 & 0.003 & 5.527 & 4.964 & 0.222 \\
\hline Income from employment in 2002 (in $€ /$ day) & 24.638 & 37.295 & 0.000 & 24.761 & 23.078 & 0.494 \\
\hline \multicolumn{7}{|c|}{ Medium economic conditions } \\
\hline Months in employment in 2002 & 4.883 & 6.845 & 0.000 & 4.923 & 4.902 & 0.963 \\
\hline Income from employment in 2002 (in $€ /$ day) & 23.829 & 47.156 & 0.000 & 24.003 & 26.260 & 0.412 \\
\hline \multicolumn{7}{|c|}{ Good economic conditions } \\
\hline Months in employment in 2002 & 5.854 & 7.571 & 0.000 & 5.709 & 5.343 & 0.425 \\
\hline Income from employment in 2002 (in $€ /$ day) & 31.068 & 55.218 & 0.000 & 31.261 & 31.114 & 0.963 \\
\hline \multicolumn{7}{|c|}{ Bridging Allowance } \\
\hline \multicolumn{7}{|l|}{ Conditional on unemployment rates } \\
\hline \multicolumn{7}{|c|}{ Poor economic conditions } \\
\hline Months in employment in 2002 & 7.242 & 6.434 & 0.025 & 7.164 & 6.628 & 0.162 \\
\hline Income from employment in 2002 (in $€ /$ day) & 47.401 & 34.154 & 0.000 & 46.390 & 39.936 & 0.035 \\
\hline \multicolumn{7}{|c|}{ Medium economic conditions } \\
\hline Months in employment in 2002 & 7.716 & 7.358 & 0.302 & 7.701 & 7.887 & 0.606 \\
\hline Income from employment in 2002 (in $€ /$ day) & 64.254 & 51.462 & 0.000 & 63.882 & 63.558 & 0.931 \\
\hline \multicolumn{7}{|c|}{ Good economic conditions } \\
\hline Months in employment in 2002 & 7.878 & 7.347 & 0.113 & 7.792 & 7.957 & 0.623 \\
\hline Income from employment in 2002 (in $€ /$ day) & 67.910 & 54.293 & 0.000 & 66.652 & 69.471 & 0.439 \\
\hline \multicolumn{7}{|l|}{ Conditional on productivity (GDP per capita) } \\
\hline \multicolumn{7}{|c|}{ Poor economic conditions } \\
\hline Months in employment in 2002 & 7.237 & 6.698 & 0.123 & 7.118 & 6.829 & 0.436 \\
\hline Income from employment in 2002 (in $€ /$ day) & 49.123 & 37.403 & 0.000 & 47.461 & 42.782 & 0.128 \\
\hline \multicolumn{7}{|c|}{ Medium economic conditions } \\
\hline Months in employment in 2002 & 7.835 & 6.845 & 0.004 & 7.832 & 7.819 & 0.970 \\
\hline Income from employment in 2002 (in $€ /$ day) & 63.685 & 47.156 & 0.000 & 63.599 & 62.838 & 0.832 \\
\hline \multicolumn{7}{|c|}{ Good economic conditions } \\
\hline Months in employment in 2002 & 7.805 & 7.571 & 0.495 & 7.690 & 8.213 & 0.155 \\
\hline Income from employment in 2002 (in $€ /$ day) & 68.293 & 55.218 & 0.000 & 66.521 & 69.243 & 0.487 \\
\hline
\end{tabular}

Note: P-value is based on a $t$-test of equal means. 
Figure A.1: Distribution of estimated propensity scores: Start-up Subsidy

Local economic conditions

Conditional on unemployment rates

$\underline{\text { Poor }}$

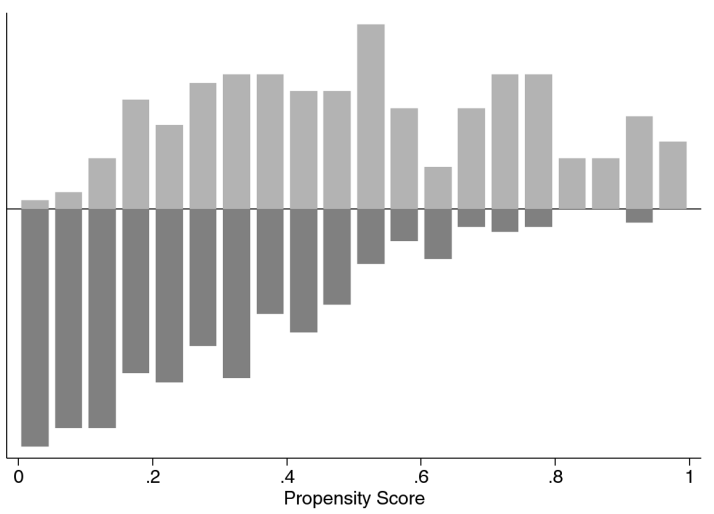

Participants off-support: 6

$\underline{\text { Medium }}$

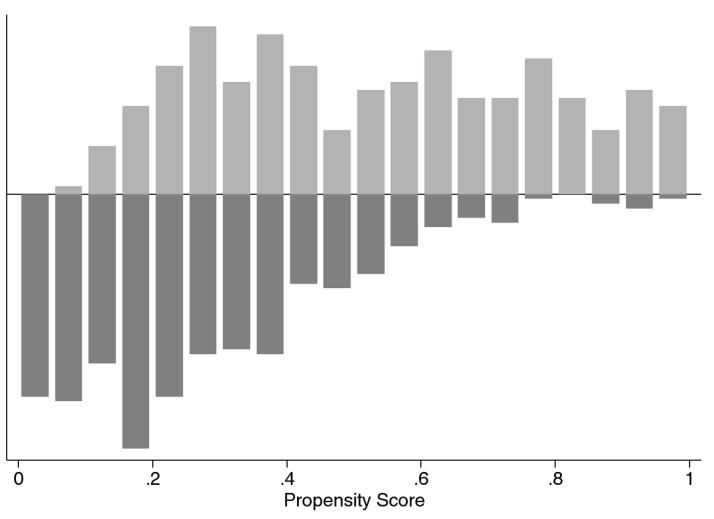

Participants off-support: 9

$\underline{\text { Good }}$

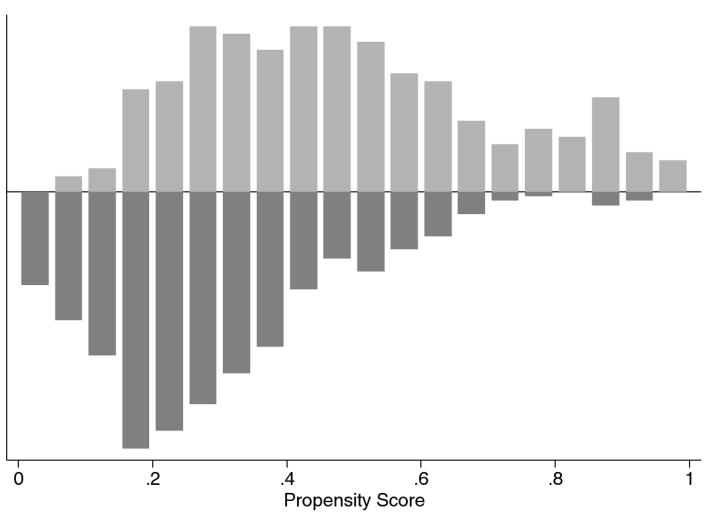

Participants off-support: 11
Conditional on productivity (GDP per capita)

$\underline{\text { Poor }}$

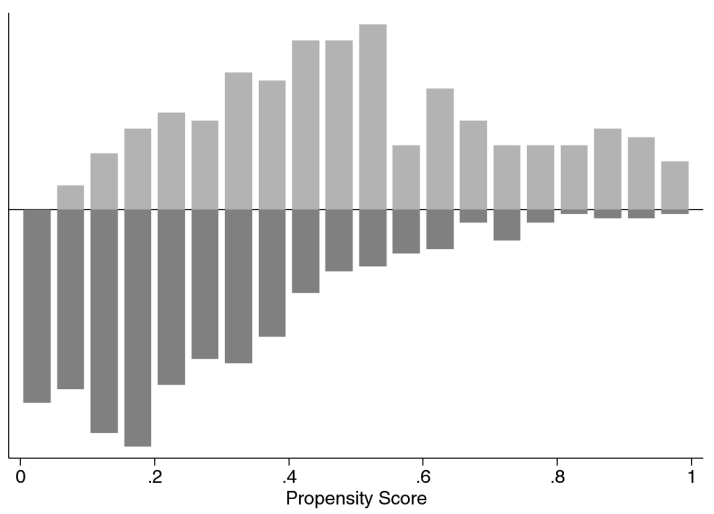

Participants off-support: 4

$\underline{\text { Medium }}$

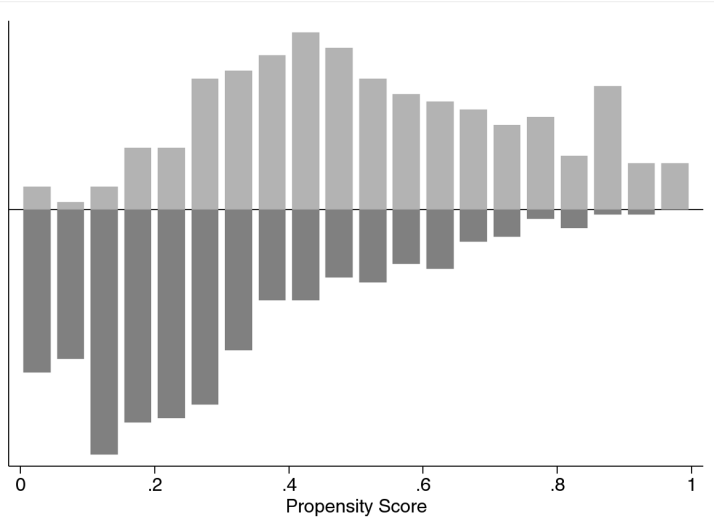

Participants off-support: 6

$\underline{\text { Good }}$

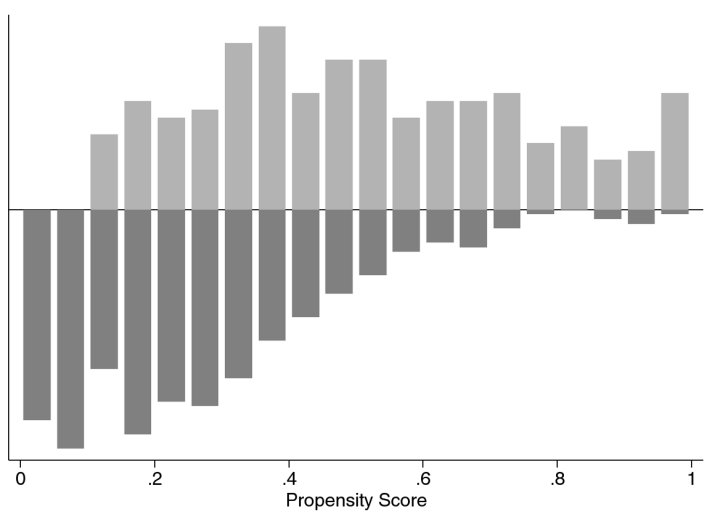

Participants off-support: 13

Participants

Non-Participants

Note: Depicted are distributions of estimated propensity scores for participants and non-participants based on probit estimations as shown in Table A.1 and Table A.2. In addition, we provide below each figure the number of participants outside the range of non-participants; those are excluded for the calculation of the ATT (as depicted in Table 4 and Figure 2). 
Figure A.2: Distribution of estimated propensity scores: Bridging Allowance Local economic conditions

Conditional on unemployment rates

Poor

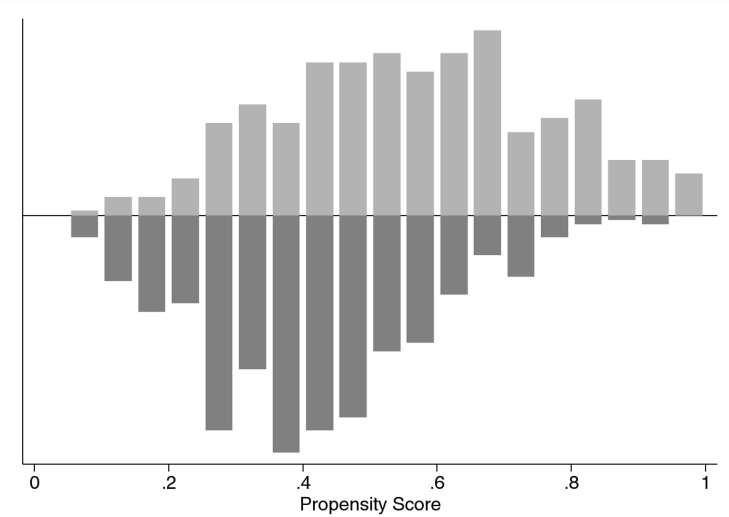

Participants off-support: 6

$\underline{\text { Medium }}$

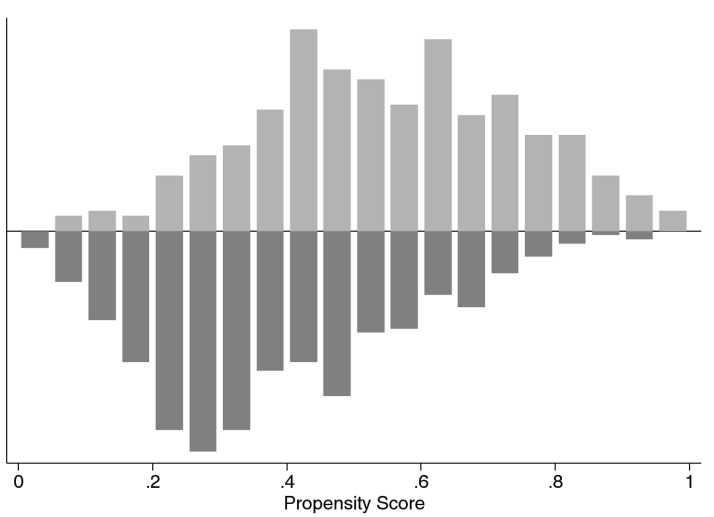

Participants off-support: 4

Good

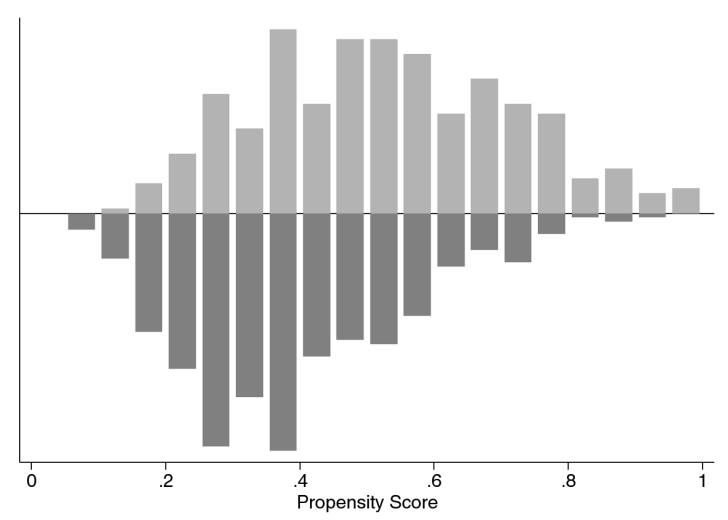

Participants off-support: 10
Conditional on productivity (GDP per capita)

Poor

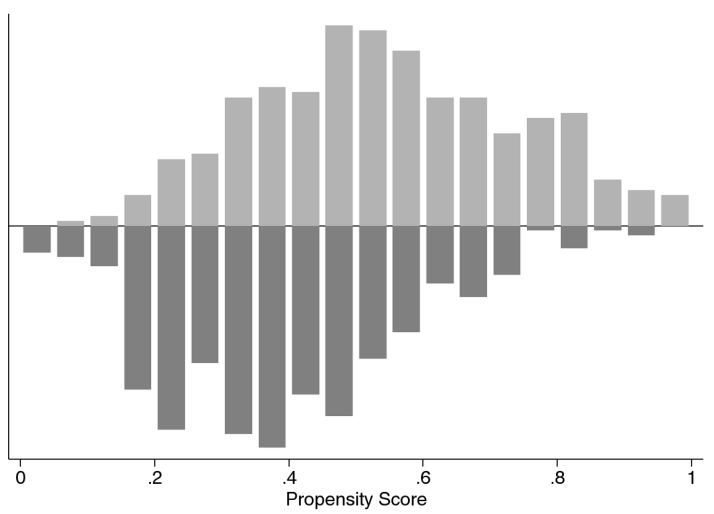

Participants off-support: 11

$\underline{\text { Medium }}$

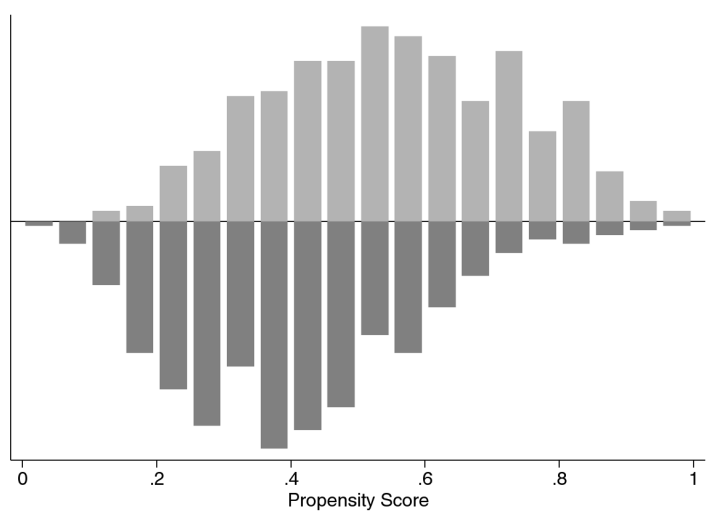

Participants off-support: 1

Good

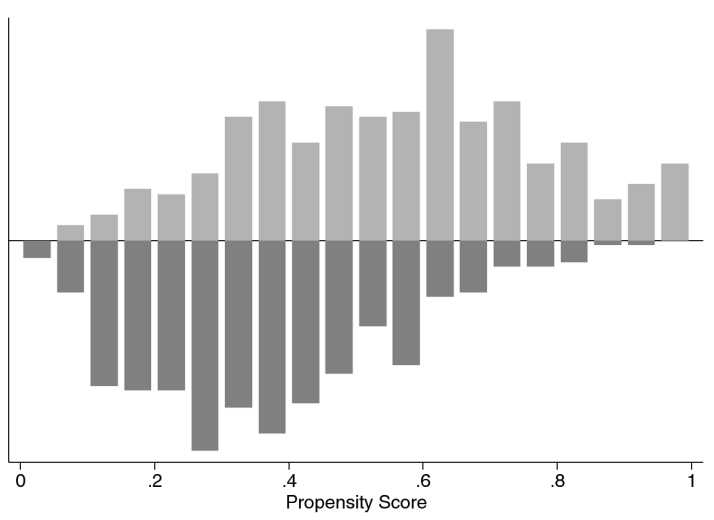

Participants off-support: 25

\section{Participants}

\section{Non-Participants}

Note: Depicted are distributions of estimated propensity scores for participants and non-participants based on probit estimations as shown in Table A.3 and Table A.4. In addition, we provide below each figure the number of participants outside the range of non-participants; those are excluded for the calculation of the ATT (as depicted in Table 4 and Figure 2). 
Figure A.3: Probability levels among participants and matched non-participants Start-up Subsidy vs. Non-Participation Bridging Allowance vs. Non-Participation Conditional on local unemployment rate
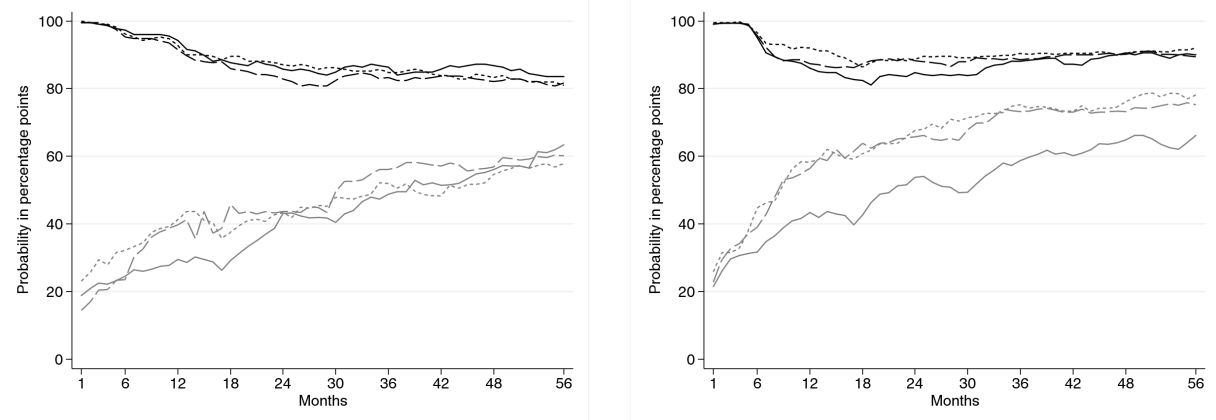

Conditional on productivity (GDP per capita)
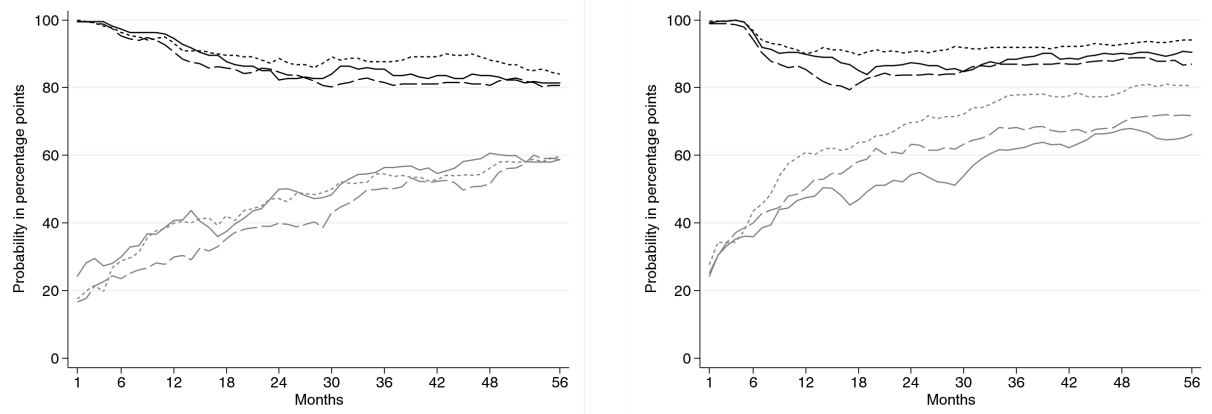

Treated (black lines) Controls (gray lines) Local economic conditions (— poor / - - - medium / - - good)

Note: Depicted are probability levels for the outcome variable "self-employment or regular employment" among participants and non-participants within the matched sample, i.e., the difference between the solid and dashed line is the average treatment effect on the treated. For instance, consider the case of start-up subsidy vs. non-participation on the left panel. $83.6 \%$ (63.4\%) of participants (matched non-participants) who were located in an area with poor economic conditions in the 3rd quarter 2003 are in self-employment or regular employment 56 months after start-up; this applies to $81.0 \%$ (57.9\%) of participants (matched non-participants) who were located in areas with good economic conditions. 